\title{
Synthesis, Characterization and Application of Disodium Tetraborate Cross-Linked Polyvinyl Alcohol Membranes for Pervaporation Dehydration of Ethylene Glycol
}

\author{
Haresh K. Dave and Kaushik Nath \\ New Separation Laboratory, Department of Chemical Engineering G H Patel College of Engineering \& Technology \\ (Gujarat Technological University) Vallabh Vidyanagar-388120 \\ *Corresponding author: E-mail: kaushiknath@gcet.ac.in (K Nath)
}

Received: 01-07-2018

\begin{abstract}
Dehydration of ethylene glycol-water mixture was carried out in a laboratory pervaporation unit using a flat sheet membrane test cell. Polyvinyl alcohol-polyether sulfone (PVA-PES) composite membranes were synthesized and cross linked with two different concentrations, viz 0.2 and $0.5 \%$ of disodium tetraborate (borax). The derived membranes were extensively characterized for their morphology, intermolecular interactions, thermo-mechanical stability, and physicochemical properties using field emission scanning electron microscopy (FESEM), atomic force microscopy (AFM), Fourier transform infrared spectroscopy (FTIR), X-ray diffraction (XRD), thermogravimetric analysis (TGA), differential scanning calorimetry (DSC) and water uptake studies. The membrane performance was evaluated in terms of pervaporation flux, separation factor, selectivity, permeability and solute diffusion coefficients of EG-water mixture at varying feed flow rate. Both in terms of flux and separation factor PVA-PES- $0.2 \%$ borax composite membrane was found superior to PVA-PES-0.5\% borax crosslinked and its uncrosslinked counterpart. Cross-linking the composite with borax produced a membrane with lower crystallinity and a smaller swelling degree, but having improved thermostability and mechanical properties.
\end{abstract}

Keywords: Pervaporation; membrane; swelling, flux; selectivity; separation factor, diffusion coefficient

\section{Introduction}

Pervaporation is much touted as an efficient and environmentally benign separation process both as a standalone unit and a supplementary to the distillation. It has been the focus of basic and applied research encompassing the membrane modification, process performance evaluation and exploration of newer areas of applications for more than three decennia. Herein we report the dehydration of ethylene glycol (EG) - a widely used precursor in organic chemical industries for the manufacturing of unsaturated polyester resins, polyacetate fibers, plasticizers antifreezing agents, lubricants, non-ionic surfactants, brake fluid, solvent and so on. Currently, direct hydration of ethylene oxide, i.e. the pressurized hydration process is the preferred route for the commercial production of EG. ${ }^{1}$ The process entails the addition of excess amount of water (about 10-25 times the molar quantity of ethylene oxide) to raise the selectivity of ethylene oxide to the EG. There- fore, the concentration of the EG obtained after completion of the reaction is at most around $10-20 \%$ by weight. EG (boiling point: $198^{\circ} \mathrm{C}$ ) dehydration by traditional multistage evaporation and distillation is highly energy intensive, requiring high pressure steam for reboiler. Here comes the importance of an alternative dehydration protocol for EG-water mixture. Several recent studies have evaluated a number of pervaporative dehydration processes of EG using an assortment of polymeric or ceramic membranes. Some of these recently used membranes include polyvinyl alcohol/hyper-branched polyester, ${ }^{2}$ polyvinyl alcohol/polypropylene, ${ }^{3}$ polyamide/polydopamine, ${ }^{4}$ polybenzimidazole/polyetherimide, ${ }^{5}$ polyvinyl alcohol-Na-zeolite mixed matrix membrane, ${ }^{6} \gamma$ - alumina-Na-zeolite, ${ }^{7}$ Na-A zeolite, ${ }^{8}$ polyvinylamine/polyvinyl alcohol-carbon nanotube ${ }^{9}$ and so on. Wu et al. (2015) reported a novel polymer of intrinsic microporosity for the separation of EG - water with separation factor of 24.2. ${ }^{4}$ Rao et al. (2007) 
prepared a cross-linked chitosan membrane with a very high separation factor of 234 in the pervaporation of EG-water mixture at $30{ }^{\circ} \mathrm{C} .{ }^{10}$ In essence, most of these works underscore the need for the optimization of the membrane formation conditions for solute transport which is largely a function of the binding interface between active and support layers.

Modification of the support layer surface of a thin film composite membrane towards a more facile permeation of the solute poses a technical challenge in the pervaporation membrane fabrication. Typically water permselective composite membranes consist of a hydrophilic active layer imparting permeability and selectivity on a hydrophobic support layer having swelling resistance propensity. ${ }^{11}$ Alleviating the surface tension and improving the interfacial interactions between these two layers have become a standard approach of the tailor-made membrane fabrication. Imparting hydrophilicity on the surface of the support layer as well as on to the bulk, ${ }^{12,13}$ incorporation of a coupling agents or surfactants ${ }^{14}$ are some of the ways in order to reap the benefit of trans-layer interfacial interaction. Additionally a strong adhesive strength between active and support layers is another prerequisite of an efficient composite membrane failing which the support layer may get peeled off and dissolve into aqueous solution. For polyvinyl alcohol (PVA) based pervaporation membranes incorporation of an interfacial cross linking agent can not only counter the inherent swelling susceptibility of PVA to ensure that the contaminants in water can be retained, but also minimize compaction under pressure while used in other pressure driven processes. ${ }^{15}$ There is a challenge for any membrane to achieve high permeate flux but not at expense of its stability and mechanical properties.

Although a growing body of literature in recent years has investigated the structural, mechanical, and thermal properties of different polymeric hydrogels, disodium tetraborate (borax) cross-linked polyvinyl alcohol composite membrane for pervaporative separation of
EG-water solution has not been extensively focused so far to the best of our knowledge. The impetus for the present work was stimulated firstly by the potential advantage of pervaporation for efficient concentration of EG from wastewater, and secondly to obtain a further insight into the permeation properties of a novel type cross linked composite membrane. The rationale of incorporating borax as a cross linking agent for PVA stems from the premise of its di-diol complexation reaction with PVA resulting in significant enhancement of its malleability. Disodium tetraborate acts as cross linking agent to bind PVA chain together. This results in the solidification of polyvinyl alcohol and trapping of water molecules, forming a slimy mass. Sodium borate dissolve in water to form boric acid, which then accepts a hydroxide from water to become $\mathrm{B}$ $(\mathrm{OH})_{4}^{-}$.

$$
\mathrm{H}_{3} \mathrm{BO}_{3}+2 \mathrm{H}_{2} \mathrm{O} \rightarrow \mathrm{B}(\mathrm{OH})_{4}^{-}+\mathrm{H}_{3} \mathrm{O}^{+}
$$

$\mathrm{B}(\mathrm{OH})_{4}^{-}$then reacts in a condensation reaction with polyvinyl alcohol as indicated in Fig. 1 Water from this condensation reaction as well as the excess water from the two solution gets trapped in the cross linked polymer which produces slimy, flexible properties. Polyvinyl alcohol- polyether sulfone (PVA-PES) composite membranes were synthesized using two different concentrations of borax as cross linking agents. The as-prepared membranes were characterized by X-ray diffraction (XRD), Fourier transform infrared spectroscopy (FTIR), scanning electron microscopy (SEM), Atomic force microscopy (AFM), mechanical testing, moisture absorption, thermogravimetric analysis (TGA) and differential scanning calorimetry. The membrane performance was evaluated in terms of pervaporation flux, separation factor, selectivity, permeability and solute diffusion coefficients of EG-water mixture at varying feed flow rate. An attempt has been made to establish their structure-property correlation. The results obtained in the present study could provide additional in-

a)

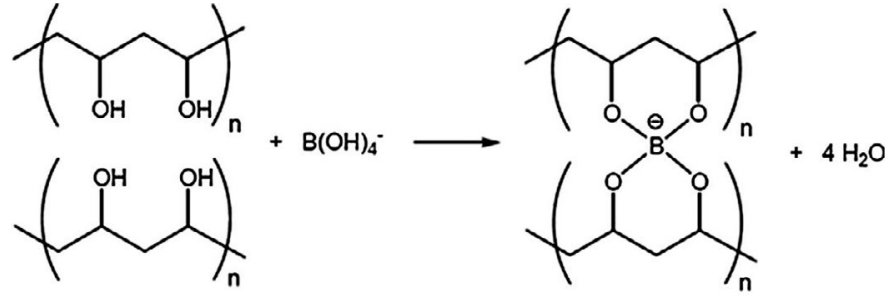

b)
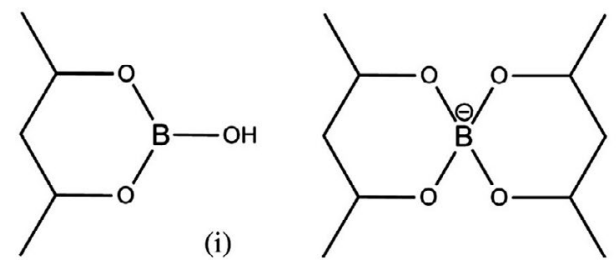

(ii)

Fig. 1. Cross linking condensation reaction of polyvinyl alcohol with borax 
put to the fundamental aspects of PVA-PES composites doped with borax for dehydration of EG on a commercial scale.

\section{Experimental}

\section{1. Chemicals}

Polyvinyl alcohol (Average molecular mass 125,000 $\mathrm{g} / \mathrm{mol}$ and degree of hydrolysis $99 \%$ ) granules, ethylene glycol and disodium tetraborate (borax) (AR grade) was purchased from S D. Fine-Chem, Mumbai, India and were used as received without additional processing. Stock solutions were prepared with deionized water obtained from a reverse osmosis system, having conductivity of $20 \mu \mathrm{S} / \mathrm{cm}$. Poly ether sulfone (PES) support membrane swatch was kindly provided by M/s Permionics Membrane Pvt. Ltd, Baroda, India. The PES ultrafiltration membrane (molecular weight cutoff of 25,000 ) was of asymmetric structure supported by nonwoven polyester fabric.

\section{2. Preparation and Cross Linking of Membrane}

The $4 \%$ by weight PVA solution was prepared by slowly stirring $4 \mathrm{~g}$ of polyvinyl alcohol powder into $96 \mathrm{~mL}$ of hot distilled water at approximately $80^{\circ} \mathrm{C}$ using magnetic stirrer. The solution was then allowed to stand in a covered container. At the same time $0.2 \%$ and $0.5 \%$ by weight sodium borate solutions were prepared by dissolving requisite amount of sodium borate decahydrate (borax) in distilled water. The as-prepared PVA solution was poured into a styrofoam cup and stirred in the sodium borate solution. The PES ultrafiltration support membranes were soaked in double distilled water for $24 \mathrm{~h}$ to remove any adherent solvent and then fully dried. The dried PES support layer was then dipped into PVA-Borax slime for $15 \mathrm{~min}$ to enhance the hydrophilicity and was subsequently pressed through a heated roller to give the uniform thickness. Dip-coating was repeated twice to ensure a complete coverage of the support layer and to minimize morphological defects. The as-prepared composite membrane was finally dried for around $24 \mathrm{~h}$ at ambient temperature.

\subsection{Pervaporation Experiment}

Pervaporation experiments were conducted in a small laboratory set-up the schematic representation of which is described elsewhere. ${ }^{16}$ The model feed solution was prepared by making four different $(50,60,70$ and $80 \%$ by volume) concentrations of EG in deionized water. The as-prepared feed was allowed to circulate continuously in contact with the membrane using a peristaltic pump from a feed tank provided with a thermostat to maintain the constant temperature of $60^{\circ} \mathrm{C}$.
Effect of flow rate on permeation flux, separation factor and diffusion coefficient were investigated by varying feed flow rate but at constant initial feed concentration and temperature. Prior to the pervaporation experiment, the membrane was allowed to equilibrate for $3 \mathrm{~h}$. The sample was collected after $2 \mathrm{~h}$ and the pervaporate compositions were analyzed by measuring its water content using an automated Karl Fisher Apparatus. Each of the pervaporation experiments was repeated two times and the results were averaged to minimize error. The experimental data points were reproducible with errors less than $5 \%$.

\section{4. Contact Angle Measurement}

The wettability of the prepared membranes used in the present study was analyzed by measuring contact angle using the sessile drop method with an optical Tensiometer. Water droplet of about $2 \mu \mathrm{L}$ of distilled water with a tight syringe was placed on the clean and dry membrane samples and the droplet was imaged. Each equilibrium contact angle was the average of the left and right contact angles, and the reported values are the average of three equilibrium contact angles.

\section{5. Thermogravimetric Analysis (TGA) and Differential Scanning Calorimetry}

The thermal degradation propensity of the as-prepared membranes were assessed as a function of increasing temperature with a TGA 2050 'Thermogravimetric Analyzer (TA Instruments)', with a ramp of $5{ }^{\circ} \mathrm{C} / \mathrm{min}$ at the temperature ranging from 40 to $900{ }^{\circ} \mathrm{C}$, under nitrogen atmosphere. The weight of the samples taken was around $10 \mathrm{mg}$. The glass transition temperature $T_{g}$ was measured by means of the extrapolated onset temperature using an in-built data analysis software.

\section{6. Fourier Transform Infrared Spectroscopy (FTIR)}

The presence of organic functional groups on the membrane surface was analyzed by the Fourier transform infrared spectroscopy (Perkin Elmer Spectrum GX) using a wave number range of $400-4000 \mathrm{~cm}^{-1}$ at a resolution of $4.0 \mathrm{~cm}^{-1}$ with an acquisition time of $1 \mathrm{~min}$. The test chamber was nitrogen purged at a flow rate of $10 \mathrm{~mL} \mathrm{~min}^{-1}$ to avoid signal interference from the surrounding moisture and $\mathrm{CO}_{2}$. At least 2 replicates were obtained for each sample type without applying any baseline corrections.

\section{7. AFM Analysis}

Atomic force microscopy (AFM) was carried out using a NT-MDT NTEGRA Aura Autoprobe CP atomic force microscope. Measurements were performed on dry membrane samples under ambient atmospheric condi- 
tions. Silicon cantilevers with integrated pyramidal tips were used to image membrane surface topography. The membrane surfaces with a scan size of $5 \mu \mathrm{m} \times 5 \mu \mathrm{m}$ were imaged in tapping mode. After image acquisition the surface roughness parameter in terms of root mean square (RMS) roughness was calculated from the AFM images using an AFM image processing toolbox.

\section{8. FESEM Analysis}

The topology of the top surface and the cross section of the prepared membranes were investigated via field emission scanning electron microscopy (FE-SEM) using JEOLFE-SEM (JSM-6701F) at 5kV under different magnifications. For cross sectional analysis, cryogenically fractured membrane samples under liquid $\mathrm{N}_{2}$ were freezedried overnight and sputtered with a thin layer of platinum using JEOL JFC-1600 auto fine coater.

\section{9. XRD Analysis}

The crystallinity of the composite polymer membranes were examined using X-Pert-MPD (Philips, Holland) $\mathrm{X}$-ray diffractometer (XRD) with $\mathrm{Cu} \mathrm{K}$ radiation of wavelength $\lambda=1.54056^{\circ} \mathrm{A}$ in the range $5^{\circ} \leq 2 \theta \leq 50^{\circ}$. The $\mathrm{X}$-ray generator was operated at an excitation voltage of 45 $\mathrm{kV}$ and a current of $40 \mathrm{~mA}$.

\section{10. Mechanical Properties}

Tensile strength, elongation at break and modulus of elasticity of the membranes used in the present work were measured using Universal Testing Machine (UTM) (Simadzu AG $100 \mathrm{KNG}$, Japan) tested at room temperature. Rectangular strips of $6 \mathrm{~mm}$ width were cut out from the polymer membrane. The strips were well gripped using thick paper during the measurement of tensile strength. The length of the specimens was $250 \mathrm{~mm}$, the thickness of the specimens was around $0.1 \mathrm{~mm}$ and the thickness was uniform to within $5 \%$ of the thickness between the grips. The load was set to maximum with a constant cross head speed of $1 \mathrm{~mm} / \mathrm{min}$.

\section{11. Degree of Swelling Measurement}

Percent degree of swelling of the prepared membranes were determined by dipping the membrane specimens into the feed solution having different concentration of EG at ambient temperature kept overnight to ensure equilibrium. The membrane specimens were then taken out and the residual surface water was wiped out smoothly by a tissue paper. The degree of swelling (DS) was estimated using Eq (1)

$$
\% D S=W_{2}-W_{1} / W_{1} \times 100
$$

where $\mathrm{W}_{1}$ and $\mathrm{W}_{2}$ are the weight of swollen and dry membranes respectively.

\section{12. Flux and Separation Factor}

The performance of pervaporation process can be determined by mainly two parameters, namely, the separation factor and the permeant flux. Using a general approach of mass transport through membranes, the flux for the compound $\mathrm{i}\left(J_{i}\right)$ is expressed as compound $\mathrm{i}$ in volume or mass divided by the permeating time and the membrane area. In gas separation, flux is normally given as a molar flux $\left(j_{i}\right)$ with units $\mathrm{cm}^{3}(\mathrm{STP}) / \mathrm{cm}^{2} \mathrm{~s}$ or $\mathrm{m}^{3}(\mathrm{STP}) / \mathrm{m}^{2}$ s. Ignoring simple numerical conversion terms $\left(\mathrm{m}^{2}\right.$ to $\mathrm{cm}^{2}$, $\mathrm{h}$ to s), it is expressed as Eq (2)

$$
J_{i}=j_{i} \frac{M_{i}}{v_{i}}
$$

Where $v_{i}$ is the molar volume of component $\mathrm{i}$ (22.4 1 (STP)/mol) and $M_{i}$ is the molecular weight of component i. The separation factor $(\beta)$ can be defined as the ratio of the molar component concentrations in the fluids on either side of the membrane. Hence:

$$
\beta=\frac{y_{i}\left(1-x_{i}\right)}{x_{i}\left(1-y_{i}\right)}
$$

Where ' $x_{i}$ ' and ' $y_{i}$ ' represent the feed and permeate concentrations of the faster permeating component $i$ which is water in the present case.

\section{13. Permeability and Membrane Selectivity}

The volumetric permeability $\left(P_{m, i}\right)$, (or permeability coefficient) and selectivity $(\alpha)$ (or ideal membrane separation factor) are the intrinsic properties of membranes under study and are independent from operating conditions (feed composition, feed stream, fluid dynamics, and permeate pressure). Following the solution-diffusion mechanism, it is defined as the transport flux of material through the membrane per unit driving force per unit membrane thickness, given as Eq. $(4)^{17}$

$$
P_{m, i}=J_{i} \frac{\delta}{\left(\gamma_{i} x_{i} P_{s}-y_{i} P_{p}\right)}
$$

Where $P_{m, i}$ is the membrane permeability, $\delta$ is the membrane thickness and $\mathrm{g}$ is the activity coefficient, which may be calculated using Van Laar eqation. The mole fraction in the feed solution is denoted as $x, P_{s}$ is the saturated vapor pressure calculated with Antoine's equation, $y$ is the mole fraction in the permeate and $P_{\mathrm{p}}$ is the permeate pressure obtained for the component during the PV experiment. It is generally denoted as Barrers (1 Barrer $=1 \times 10^{-10} \mathrm{~cm}^{3}(\mathrm{STP}) \mathrm{cm} / \mathrm{cm}^{2} \mathrm{~s} \mathrm{~cm} \mathrm{Hg}$ ) for the gas 
separation. Alternatively, when the membrane thickness is not known, membrane permeance $\left(P_{m, i} / \delta\right)$, ratio of membrane permeability to membrane thickness can be used. Permeance is most commonly reported as gas permeation unit $(\mathrm{gpu})\left(1 \mathrm{gpu}=1 \times 10^{-6} \mathrm{~cm}^{3}(\mathrm{STP}) \mathrm{cm} / \mathrm{cm}^{2} \mathrm{~s}\right.$ $\mathrm{cm} \mathrm{Hg}$ ).

The membrane selectivity is defined as the ratio of the permeabilities or permeances of components $i$ and $j$ through the membrane is given by Eq. (5)

$$
\beta=\frac{P_{m, i}}{P_{m, j}}
$$

Both selectivity and separation factor parameters quantify how compound i is preferably permeated through a certain membrane material when compared to the permeation of compound $j$.

\section{14. Diffusion Coefficient}

In a binary mixture, Fick's law is often used to describe the binary diffusion, which can be expressed as

$$
J_{i}=-D_{i} \frac{d C}{d \delta}
$$

where $J_{i}$ is the permeation flux of component i per unit area $\left(\mathrm{kg} / \mathrm{m}^{2} \mathrm{~h}\right), D_{i}$ is the diffusion coefficient of component $\mathrm{i}\left(\mathrm{m}^{2} / \mathrm{s}\right)$, C is the concentration of permeant $\left(\mathrm{kg} / \mathrm{m}^{3}\right)$ and $\delta$ $(\mathrm{m})$ is the diffusion length or the thickness of the PVA active layer only, as diffusion is assumed to take place through this layer only. The concentration profile in this study is as- sumed to be linear along the diffusion length. As a result, transport Eq (6) can be rewritten as ${ }^{16}$

$$
D_{i}=\frac{J_{i} \delta}{C}
$$

\section{Results and Discussion}

\section{1. FTIR Analysis}

The systematic interpretation of the FTIR spectrum can be of great help in determining the presence of functional groups in the test samples. FTIR spectra of the cross linked composite membranes with two different concentration of borax over wave numbers of $4000-400 \mathrm{~cm}^{-1}$ are presented in Fig. 2. In the indicated wave number range, both the PES support-layer and PVA skin layers of the composite membranes could be sampled due to the relatively deep penetration depth $(>300 \mathrm{~nm})$. Principal band assignments of FTIR spectra are presented in Table 1. Formation of PVA-PES composite membranes is modulated by the addition of a cross-linking agent, borax in the present study, which leads to the formation of esters with hydroxyl groups on the polymer network. ${ }^{18} \mathrm{~A}$ close inspection of the FTIR spectra as presented in Figure 2 indicates the presence of a number of sharp, medium and broad peaks in the entire range of $400-4000 \mathrm{~cm}^{-1}$. The sharp peaks at 3438.52 and $3452.92 \mathrm{~cm}^{-1}$ were observed due to $\mathrm{O}-\mathrm{H}$ stretching vibration - an indicative of the presence of unreacted $\mathrm{OH}$ group, but this was partly broadened as a result of $\mathrm{H}$-bonding interaction. The characteristic bands between 2925 and $2934 \mathrm{~cm}^{-1}$ are due to symmetric and

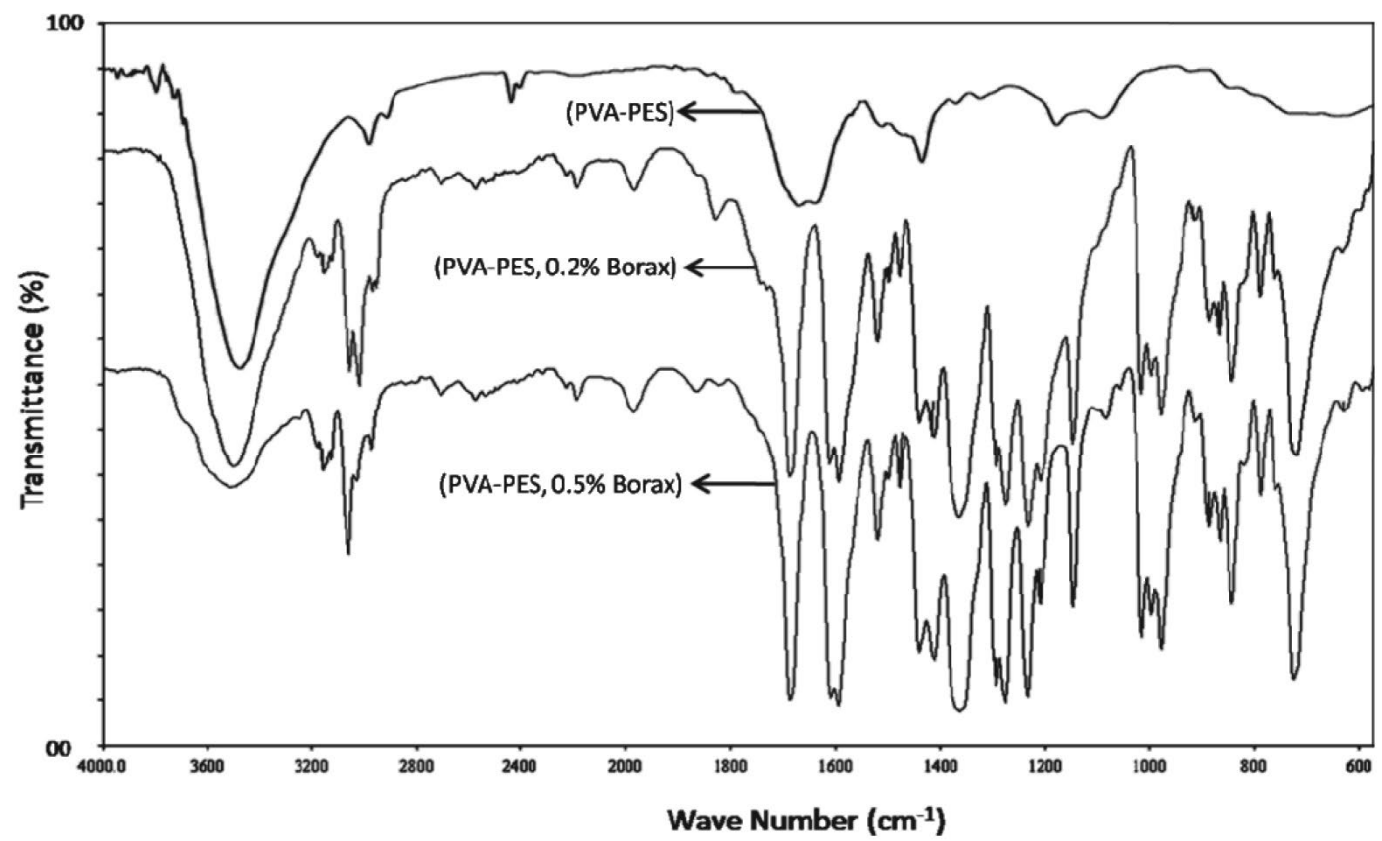

Fig. 2. FTIR spectra of PVA-PES composite membrane specimens cross linked with $0.2 \%$ and $0.5 \%$ borax as cross-linking agent used in the present study 
Table 1. Principal band assignments of FTIR spectra over wave number $4000-400 \mathrm{~cm}^{-1}$

\begin{tabular}{ccl}
\hline $\begin{array}{c}\text { Wave numbers }\left(\mathbf{c m}^{-\mathbf{1}}\right) \\
\text { Crosslinked with } \\
\mathbf{0 . 5 \%} \text { borax }\end{array}$ & Band Assignments \\
\hline 3438 & 3452 & O - H stretching vibration \\
2925 & 2968 & C-H Stretching vibration \\
1738 & 1776 & H-O-H bending (lattice, interstitial water) \\
1409.19 & 1409.06 & Asymmetric stretching relaxation of B-O-C (Trigonal $\mathrm{BO}_{3}$ group) \\
1364.24 & 1324 & Asymmetric stretching relaxation of $\mathrm{B}-\mathrm{O}-\mathrm{C}$ (Tetrahedral $\mathrm{BO}_{4}$ group) \\
$1103.86,1013.01$ & $1106.07,1073.52$ & Asymmetric stretching vibration of $\mathrm{B}_{4}-\mathrm{O}$ \\
873.47 & 873.96 & Symmetric stretching of $\mathrm{B}_{3}-\mathrm{O}$ \\
854 & 853 & Symmetric stretching of $\mathrm{B}_{4}-\mathrm{O}$ \\
832 & 834 & B-O stretching from residual $\mathrm{B}(\mathrm{OH})_{4}$ \\
688.61 & 691.18 & Bending of B-O-B linkages within borate network \\
834.33 & 877.92 & In-phase out-of-plane hydrogen deformation of para-substituted phenyl groups \\
735 & 716 & Out of plane bending of B-O-H \\
688 & 691 & Symmetric pulse vibration of triborate and hexaborate anion. \\
558 & 565 & Bending of $\mathrm{B}_{3}-\mathrm{O}$ and $\mathrm{B}_{4}-\mathrm{O}$ \\
\hline
\end{tabular}

asymmetric $\mathrm{C}-\mathrm{H}$ stretching vibrations. There was no major visible influence on peak intensity of $\mathrm{C}-\mathrm{H}$ stretching bands in any of the composites. The spectra of the $0.2 \%$ and $0.5 \%$ borax cross-linked PVA-PES composites show a number of additional bands between $400-1400 \mathrm{~cm}^{-1}$. Two types of complexes can be formed between PVA and borate; trigonal and tetrahedral. ${ }^{19}$ The band near 1409.19 $\mathrm{cm}^{-1}$ is presumably due to the asymmetric stretching relaxation of $\mathrm{B}-\mathrm{O}-\mathrm{C}$ linkage in trigonal $\mathrm{BO}_{3}$ group, whereas that near $1324-1364 \mathrm{~cm}^{-1}$ is due to asymmetric stretching relaxation of $\mathrm{B}-\mathrm{O}-\mathrm{C}$ in tetrahedral $\mathrm{BO}_{4}$ group. A rough comparison of peak of the two $\mathrm{B}-\mathrm{O}-\mathrm{C}$ stretching indicates that that trigonal complex have sharper and larger peaks and are more prominent within the membrane than their tetrahedral counterparts. The free hydroxyl groups on trigonal complexes for potential hydrogen bonding with PVA-PES composite leading to a dominant interaction system within the hydrogels. The bands in the vicinity of $1073-1103 \mathrm{~cm}^{-1}$ are due to asymmetric stretching vibration of $\mathrm{B}_{4}-\mathrm{O}$ bonds. The bands near $873.47-873.96 \mathrm{~cm}^{-1}$ and $854-853 \mathrm{~cm}^{-1}$ are due to symmetric stretching of $\mathrm{B}_{3}-\mathrm{O}$ and $\mathrm{B}_{4}-\mathrm{O}$ bonds respectively. ${ }^{20}$ This band correlates to hydroxyl groups that have complexed (formed crosslinks) with borate ions and those involved in intermolecular hydrogen bonding. The peak at $2924 \mathrm{~cm}^{-1}$ was attributed to $\mathrm{CH}$ stretching of the $\mathrm{CH}_{2}$ group. ${ }^{18} \mathrm{~A}$ perusal of the spectra indicates the presence of certain principal bands in the cross-linked membranes, although some of them were diluted significantly or shifted to relatively to lower wave numbers as a result of cross linking complexation reaction. Although borax crosslinked PVA-PES composite membrane with two different proportion of borax exhibited peaks in the range of $1324-1409 \mathrm{~cm}^{-1}$, confirming crosslink formation, a considerable amount of the borate within these hydrogels appeared to preferentially form networks amongst themselves.

\section{2. Thermogravimetric Analysis}

Heat resistance and thermal stability of the polymeric membranes as a function of increasing temperature (with constant heating rate) were studied using thermogravimetric analysis.

TGA characterizations of the cross-linked composite membranes having $0.2 \%$ and $0.5 \%$ borax cross linking are shown in Fig. 3. A perusal of TGA thermograms show that the weight loss for both the composite membranes started at about $380^{\circ} \mathrm{C}$. There were two consecutive stages of weight loss. The first weight loss starting at about $380^{\circ} \mathrm{C}$ was mainly due to desorption of the adsorbed water molecules while the 2 nd stage of weight loss from $400{ }^{\circ} \mathrm{C}$ to $450{ }^{\circ} \mathrm{C}$ was plausibly contributed by the elimination of the side groups or the

thermal desulfonation. The first stage of weight loss was very small about $1.07 \%$ but the weight loss at second stage was significant (about $42.15 \%$ ). A further weight loss of about $33.97 \%$ took place at the $3^{\text {rd }}$ stage in the vicinity of $500{ }^{\circ} \mathrm{C}$. This was corresponding to the degradation of the polymeric backbone. ${ }^{21,22}$ At this temperature range, the degradation of PVA occurs, leading to the formation of water, acetaldehyde, acetone, ethanol, etc. In general the primary structural decomposition of PVA membranes occurs in the vicinity of $275^{\circ} \mathrm{C}$ temperature but it shifted to nearly $380{ }^{\circ} \mathrm{C}$ for cross-linked PVA sample, suggesting considerable stability enhancement due to the formation of homogeneous cross linked layer. Clearly, cross linked PVA membrane used in the study imparted sufficient thermal stability. This was due the restriction of the amount of water inside the membrane network as a result of cross linking. Additionally, we notice that the difference in weight loss of the used PVA membrane after a repeated cycle of operation was not much different from the original membrane. Taken together, these findings implicate that that both the membranes possess considerable thermal stability over a wide temperature range. 


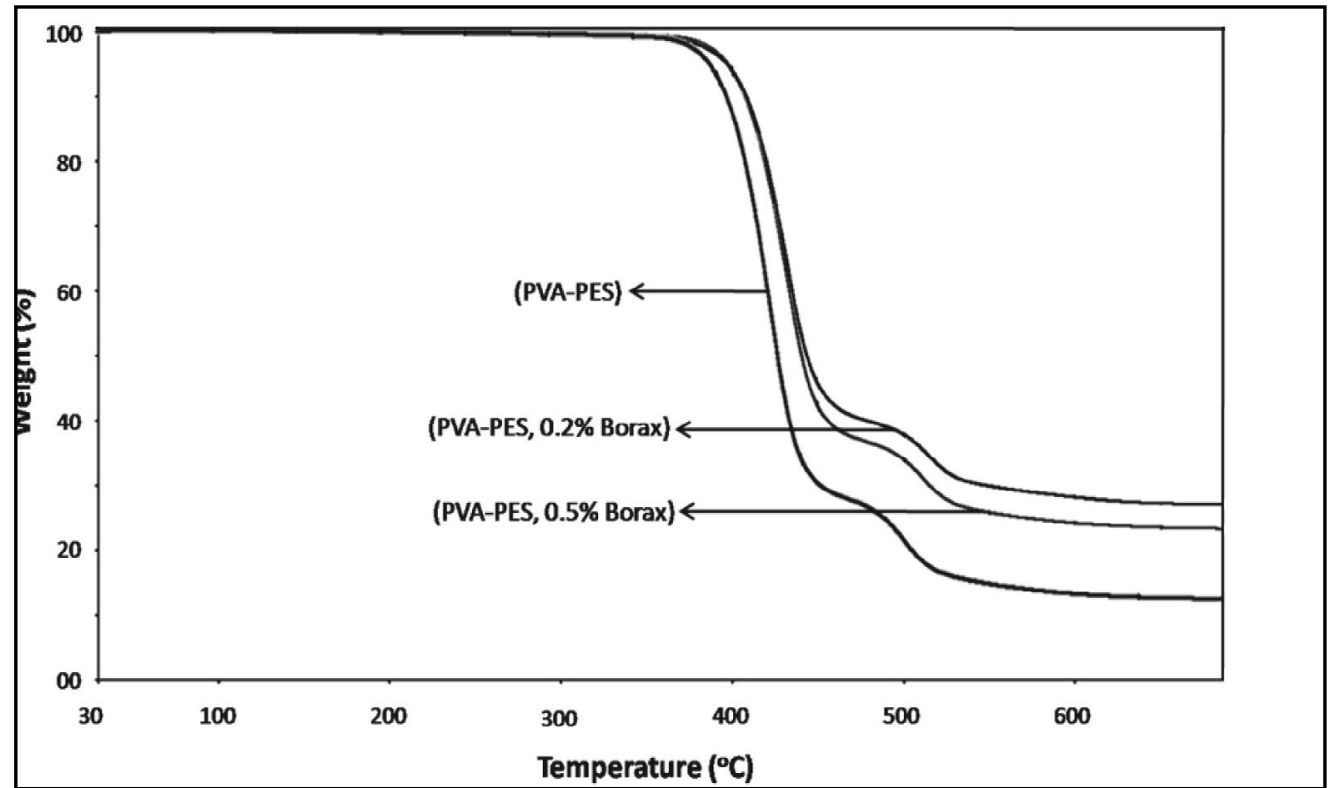

Fig. 3. TGA thermograms of PVA-PES composite membrane specimens cross linked with $0.2 \%$ and $0.5 \%$ borax as cross-linking agent used in the present study.

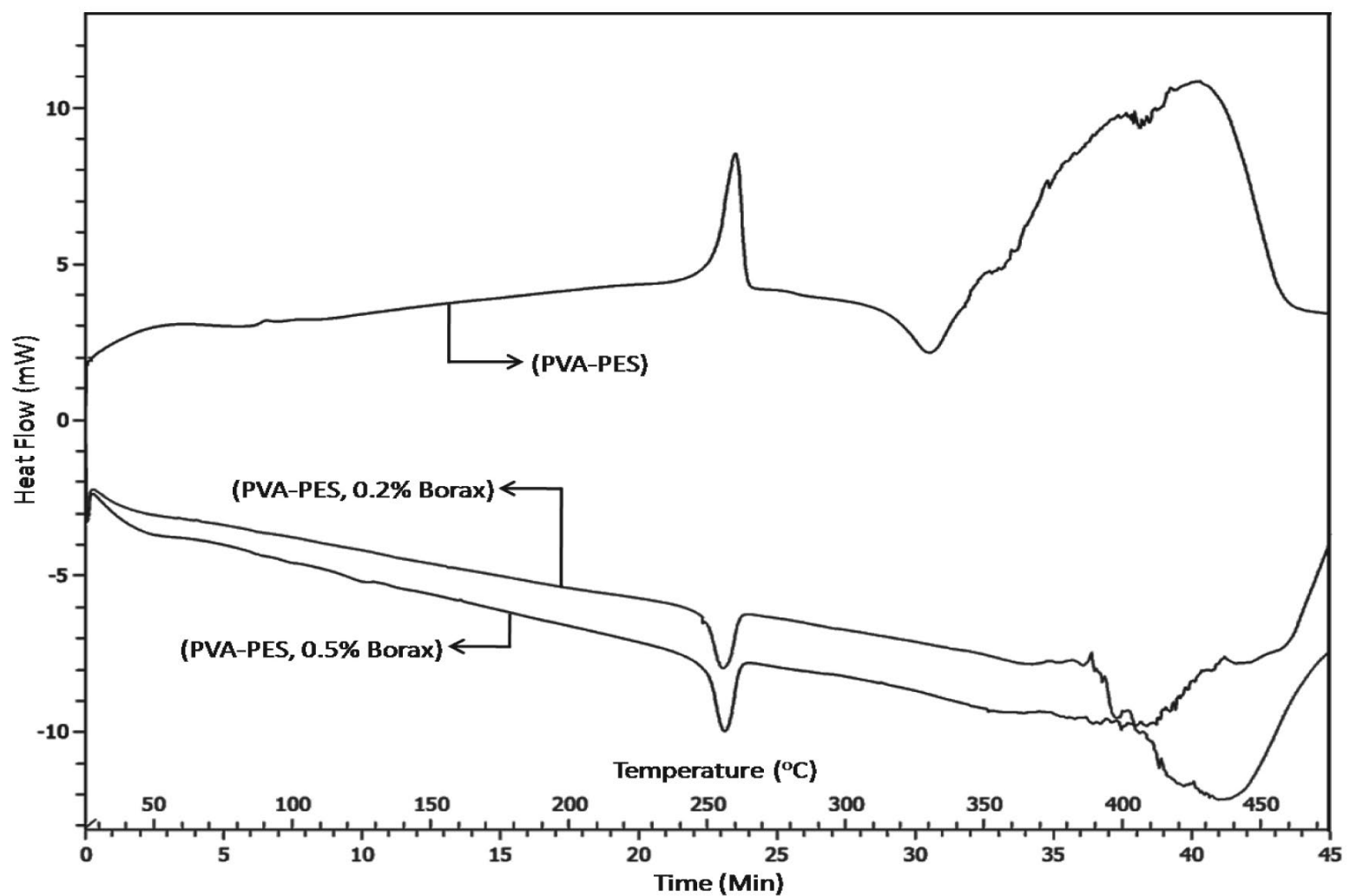

Fig. 4. Differential Scanning Calorimetry thermograms of the prepared composite membranes used in the present study.

\section{3. Differential Scanning Calorimetry}

Differential scanning calorimetry (DSC) was used to investigate the response of polymers to heating. The analogue differential scanning calorimetry study can be used to predict the miscibility behavior for the blending of polymer by measuring their heat of mixing. ${ }^{23,24}$ In the present study it was applied to determine the melting temperature, glass transition temperature and latent heat of melting of the prepared composite membranes. In semi-crystalline 
polymer of any type the glass transition is the best indicator of material properties. As the glass transition changes due to either different degrees of polymerization or modification by additives, the physical properties of the material change. DSC thermograms of the prepared composite membranes are presented in Fig. 4. There were two exothermic up-peaks and one down-peak found in the thermogram of uncrosslinked membrane specimen, while in the borax cross-linked membranes one endothermic up and two down peaks were observed. The endothermic peaks indicate that the heat of mixing of polymer is positive. ${ }^{25}$ The first, second and third peaks were the indications of $\mathrm{T}_{\mathrm{g}}$ (glass transition temperature), $\mathrm{T}_{\mathrm{c}}$ (crystalline temperature) and $\mathrm{T}_{\mathrm{m}}$ (melting temperature) respectively. The glass transition temperature of the uncrosslinked PVA-PES membrane was found out to be $87.86^{\circ} \mathrm{C}$, while the same for $0.2 \%$ and $0.5 \%$ borax cross-linked membranes were $100^{\circ} \mathrm{C}$ and $110{ }^{\circ} \mathrm{C}$ respectively. Increase in the $\mathrm{T}_{\mathrm{g}}$ value confirms the cross-linking of borax with polyvinyl alcohol (PVA) as the polymers can not be blended below their glass transition temperatures ${ }^{26}$ Crosslinking the membrane with borax restricts the segmental motion of its chain resulting in enhancement of glass transition temperature. ${ }^{27}$ It was also observed from the thermogram that after around $480^{\circ} \mathrm{C}$, the behavior of the peaks became random. The crystallinity temperature of the three membranes were found out to be 251.1 (uncrosslinked), 248.49 ( $0.2 \%$ borax crosslinked $)$ and $261.89^{\circ} \mathrm{C}(0.5 \%$ borax crosslinked) respectively. On the other hand the melting temperatures of the same were $315,435.29$, and $477.99^{\circ} \mathrm{C}$ respectively. The melting temperature $\left(\mathrm{T}_{\mathrm{m}}\right)$ in a DSC indicates not only the onset of melting but also the peak temperature, which corresponds to complete melting in or- ganics and the energy that the melting transition needs in order to occur. This is the enthalpy of the transitions, and it is associated with the crystallinity of materials.

\section{4. XRD Analysis}

The X-ray diffraction measurement was carried out to observe the crystallinity of the composite polymer membrane. The sharp diffraction maxima in the X-ray diffractogram indicate the presence of crystalline region of the polymer while the broad maxima are the representative of semi-crystalline to amorphous phases. Fig. 5 represents the wide angle

$\mathrm{X}$ ray diffraction pattern of the borax cross-linked PVA-PES composites membranes used in the present study with two different borax concentrations viz $0.2 \%$ and $0.5 \%$. The X-ray diffractogram reveals the presence of a sharp peak at $2 \mathrm{q}=15^{\circ}$ and a minor peak at $2 \mathrm{q}=25^{\circ}$ corresponding to the borate ions, originated from the borax in aqueous solution. $\mathrm{Na}_{2} \mathrm{~B}_{4} \mathrm{O}_{7}$ hydrolyzes in solution to produce $\mathrm{B}(\mathrm{OH})_{4}^{-}$. This reacts with the $-\mathrm{OH}$ groups on PVA to generate a cross linked structure. XRD pattern of uncross-linked PVA membrane is also given in Figure 5 for comparison. The un-crosslinked pristine PVA membrane shows diffraction peak at $2 \theta=20^{\circ}$ due to the mixture of $\{10$ $1\}$ and $\left\{\begin{array}{lll}2 & 0 & 0\end{array}\right\}$ crystalline plane Bragg reflections, typical for an orthorhombic lattice. ${ }^{28}$ For pure PVA, the crystallinity was high due to the hydroxyl groups in its side-chain. When borax content was lower $(0.2 \%)$ the steric effect and hydrogen bonding between PVA and borax in the cross-linking network interfered the ordered packing of PVA polymer chains, which resulted in a compression of amorphous region and thereby prevented from the forma-

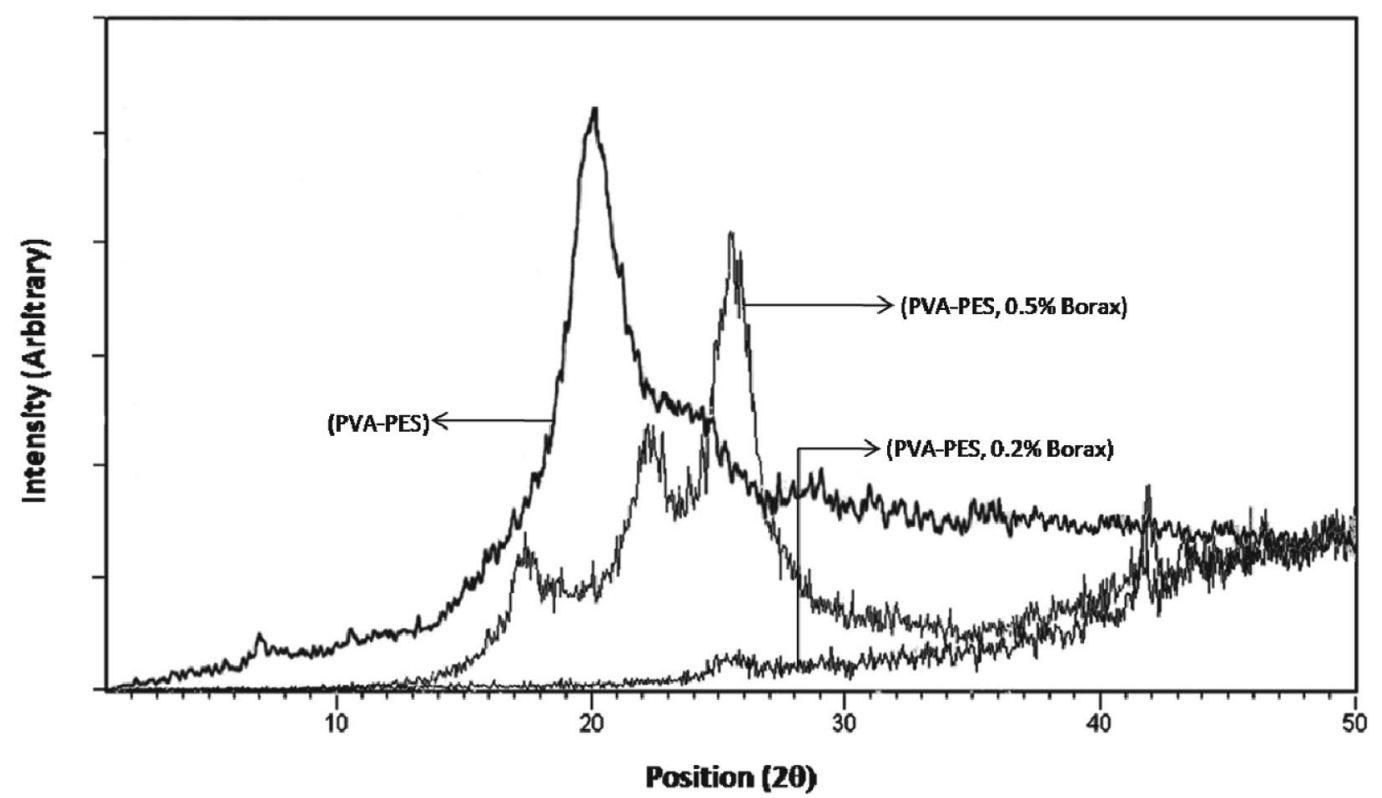

Fig. 5. Wide angle $\mathrm{X}$ ray diffraction pattern of the borax cross-linked PVA-PES composites membranes used in the present study with two different borax concentrations viz $0.2 \%$ and $0.5 \%$. 
a)

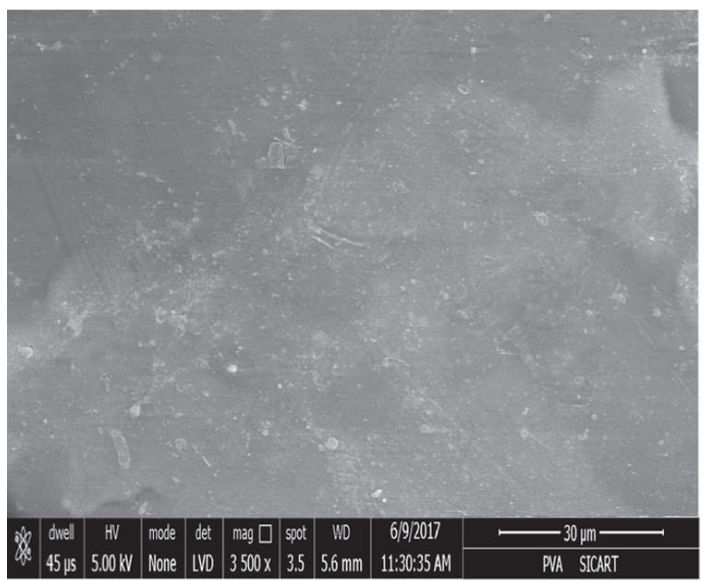

c)

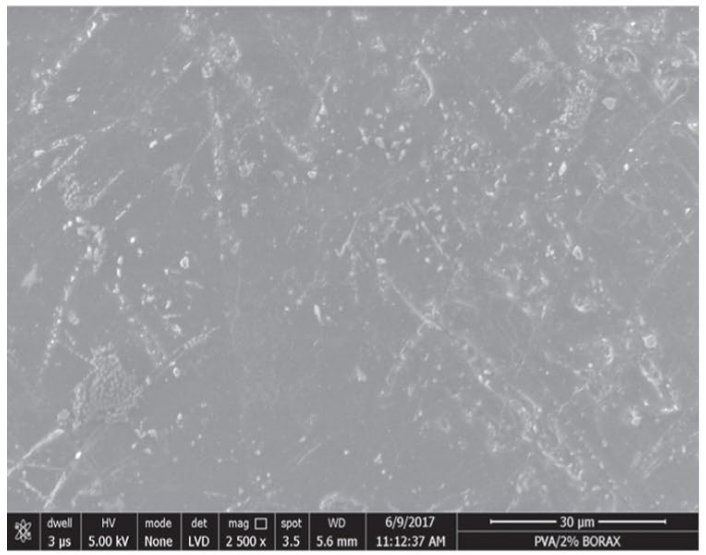

e)

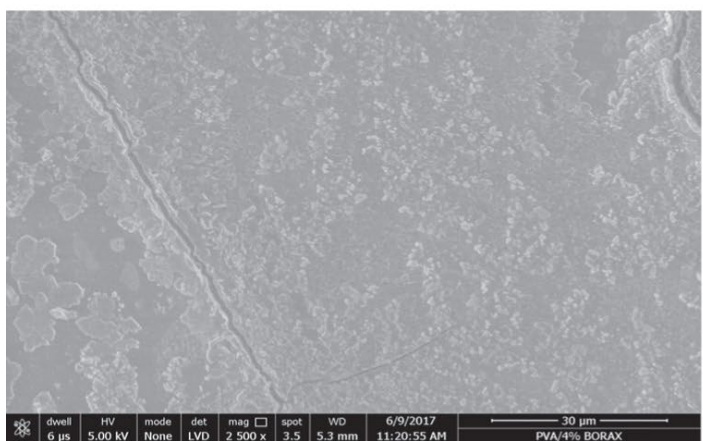

b)

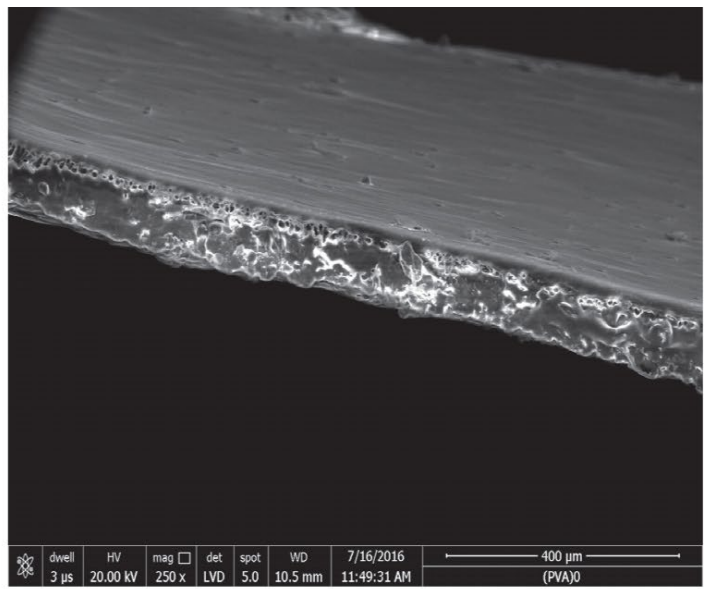

d)

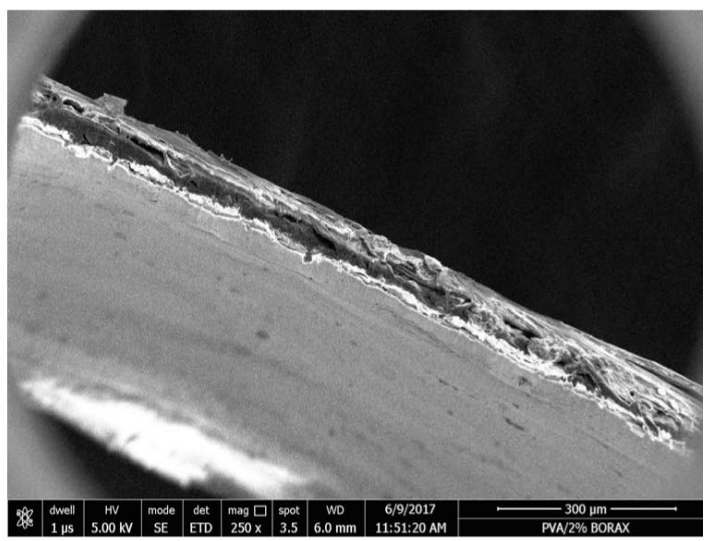

f)

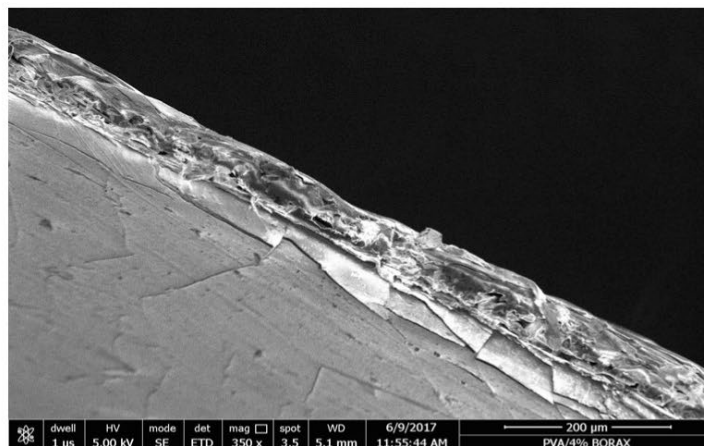

Fig. 6. Scanning electron micrographs of the top surface and cross sections of the uncrosslinked PVA-PES composite, and PVA-PES composite membrane specimens doped with $0.2 \%$ and $0.5 \%$ of borax crosslink (a: uncrosslinked PVA -PES top surface, magnification: 3500 ; b: uncrosslinked PVA-PES cross section, magnification: 250; c: PVA-PES-0.2\% borax top surface, magnification: 2500 ; d:PVA-PES- $0.2 \%$ borax cross section, magnification 250; e: PVA-PES-0.5\% borax top surface, magnification: 2500; f: PVA-PES-0.5\% borax cross section, magnification: 350 )

tion of crystalline region. Crystallinity of polymeric membranes is closely linked with the solute transport properties.

The permeability in a semi crystalline polymer membrane is substantially lower than that in an amorphous due to reduction of spaces available for diffusion and the tortuous path around the crystallites. ${ }^{29}$ Thus, an overall decrease in the relative crystallinity was observed in PVA-PES com- posite membrane crosslinked with $0.2 \%$ borax as compared to that crosslinked with $0.5 \%$ borax.

\section{5 Surface Morphology by SEM Analysis}

Scanning electron micrographs of the top surface as well as cross sections of the uncrosslinked PVA-PES composite, and PVA-PES composite membrane specimens 
doped with $0.2 \%$ and $0.5 \%$ of borax crosslinker respectively are presented in Fig. 6. A perusal of the SEM micrographs reveals that the surface topography of the un-crosslinked PVA-PES membrane appears smooth and dense having continuous matrix without much visibility of pores or fissures and with good structural integrity. SEM images of the high and low molecular weights poly (vinylidene fluoride) blend membranes revealed asymmetric structures with finger- like macro-voids and sponge-like layer. ${ }^{30}$ The granules shape of PVA indicates some crystalline behavior occurring in the uncrosslined PVA-PES composite polymer (Fig.6-a). On the other hand the surface morphology of the cross linked composite polymer sample shows many different sizes of aggregates or chunks that are randomly distributed on the top surface. The cross-section of the SEM image shows some more void space in the borax crossliked membrane. The presence of this void space might have contributed to the high flux of the membrane. ${ }^{31}$ With increasing the amount of crosslinker, the surface of the PVA-PES composite membranes tends to become less gritty compared to their uncrosslinked counterparts (Fig. 6-b). Apparently, the crosslinker gradually densifies the membrane surface. Nevertheless, small defects were visible in the structures of the cross linked membranes. The cross sections of the composite membranes showed a compaction and densification with increasing amount of crosslinker. From the SEM micrographs the total thickness of the PVA-PES membranes was estimated to be approximately $105 \pm 10$ $\mathrm{mm}$ and that of the active layer thickness was $34.60 \mathrm{~mm}$. Both the membranes exhibited a porous cross-section at higher magnification. The support materials successfully helped the coating layer maintain the pore channel Structure. ${ }^{32}$ By increasing the amount of crosslinker up to 0.5 $\mathrm{wt} \%$, the structure became denser and uniform (Figure 6-c). This confirms the result obtained for the surface analysis of the membrane. It is flat and compact with very sparsely distributed small particles without any phase separation.

\section{6. Surface Topography by AFM Analysis}

Atomic force microscopy (AFM) was used to analyze the surface topography and roughness of the prepared composite membranes. Roughness is one of the most important surface properties having strong influence on ad- hesion as well as membrane transport. Adhesive force becomes larger for membranes with high roughness compared to the smoother ones. AFM images of the uncrosslinked and cross linked PVA-PES membranes are presented in Fig. 7. A close inspection of the images recorded for PVA/PES composite membranes confirm that borax cross linking has imparted rougher surfaces. The virgin PVA/ PES membrane has smoother structure than the modified membranes with borax. Root-mean-square (RMS) height is a key physical parameter obtained from the AFM analysis, and defines as the mean of the root for the deviation from the standard surface to the indicated surface. The high RMS means high surface roughness. RMS roughness, average roughness and the contact angles of the membrane specimens from the present study are presented in Table 2 . It indicates that RMS roughness of the uncrosslinked PVAPES composite was $44.63 \mathrm{~nm}$ which increased to 52.24 and $53.17 \mathrm{~nm}$ in the specimens cross linked with $0.2 \%$ and $0.5 \%$ borax respectively.

Data presented in Table 2 reflect higher standard deviation for borax crosslinked membrane. Higher standard deviation represents higher surface roughness of composite membranes. ${ }^{33}$ Similar observations were reported by Rana et al (2012) ${ }^{34}$ for the cellulose membrane by the addition of $3 \mathrm{wt} \%$ additives of charged surface modifying macromolecule and poly(ethylene glycol). The membrane thus prepared was reported to decrease the surface contact angle and increase the roughness of membrane. ${ }^{34}$ Contact angle, which is an indication of hydrophilicity of the membrane, was also high for the un-crosslinked PVAPES composite membranes. Hydroxyl-terminated polybutadiene (HTPB) blended poly(ether sulfone) (PES) membranes also showed the decreasing trend of contact angles by adding solvents such as N-methyl-2-pyrrolidinone (NMP) and N,N-dimethylacetamide (DMAc). ${ }^{31} \mathrm{On}$ the other hand, the increase in RMS and average roughness parameters was accompanied by the decrease in contact angles. This implies that unmodified PES-PES composites had less hydrophilicity compared to their crosslinked counterparts.

\section{7. Mechanical Properties}

The mechanical properties of the PVA-PES composite membranes cross linked with borax are presented in Table 3 . The values indicate that the tensile stress and the

Table 2. Roughness parameters and contact angles of the membrane specimens in AFM image analysis (Sampling area $5 \mu \mathrm{m} \times 5 \mu \mathrm{m}$ ) (The figures in the bracket in column 4 indicate standard deviation.)

\begin{tabular}{lccc}
\hline Membrane specimens & $\begin{array}{c}\text { RMS roughness } \\
(\mathbf{n m})\end{array}$ & $\begin{array}{c}\text { Average roughness } \\
(\mathbf{n m})\end{array}$ & $\begin{array}{c}\text { Contact angle } \\
\mathbf{( \mathbf { o } )}\end{array}$ \\
\hline PVA-PES & 44.63 & 41.69 & $52.5( \pm 0.43)$ \\
PVA-PES-Borax 0.2\% & 52.24 & 38.25 & $49.4( \pm 0.58)$ \\
PVA-PES-Borax 0.5\% & 53.17 & 43.16 & $45.6( \pm 0.76)$ \\
\hline
\end{tabular}


a)
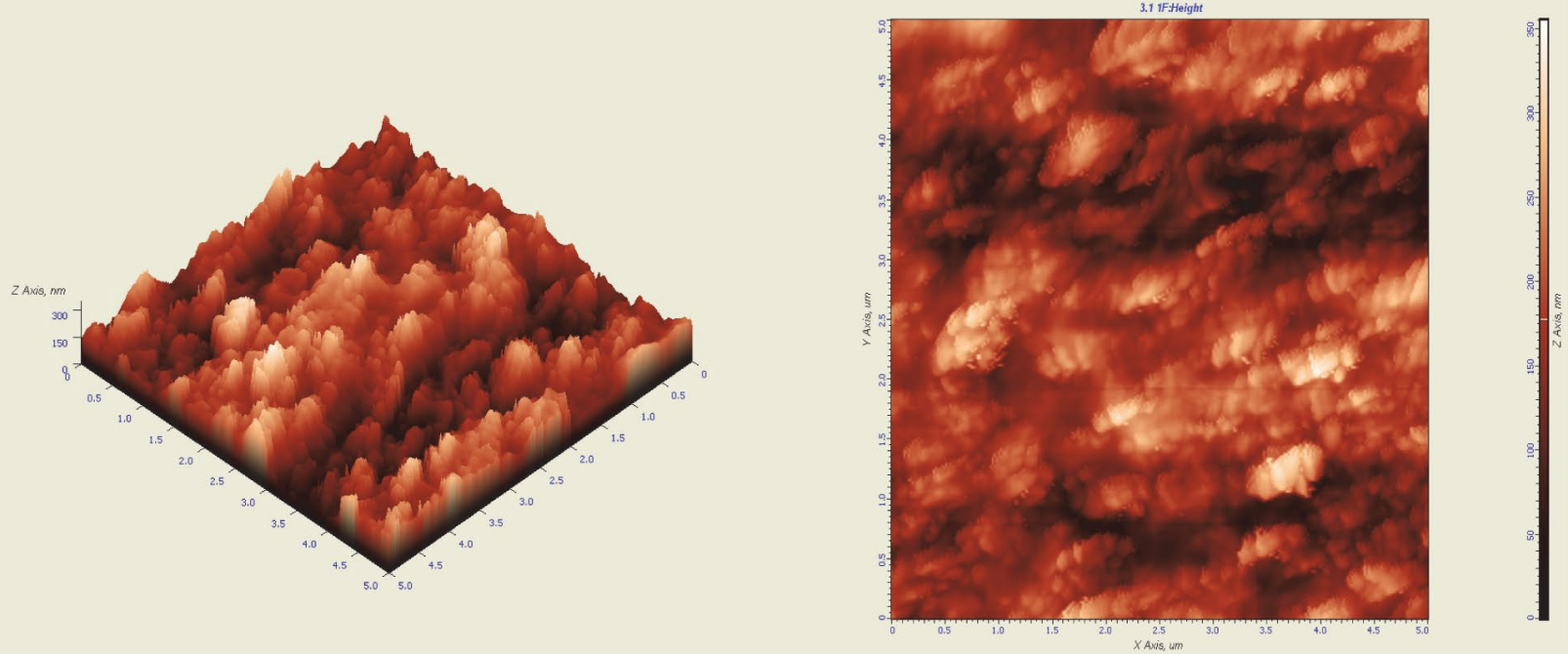

b)
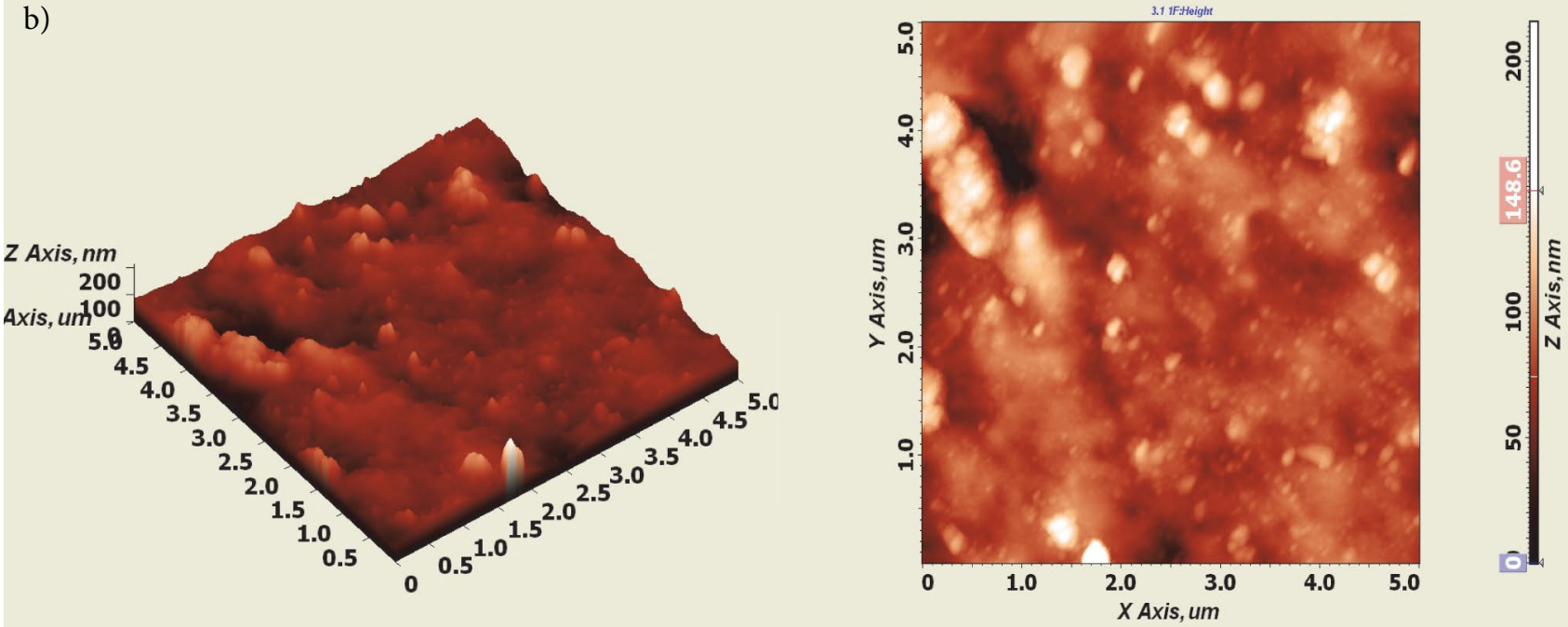

c)
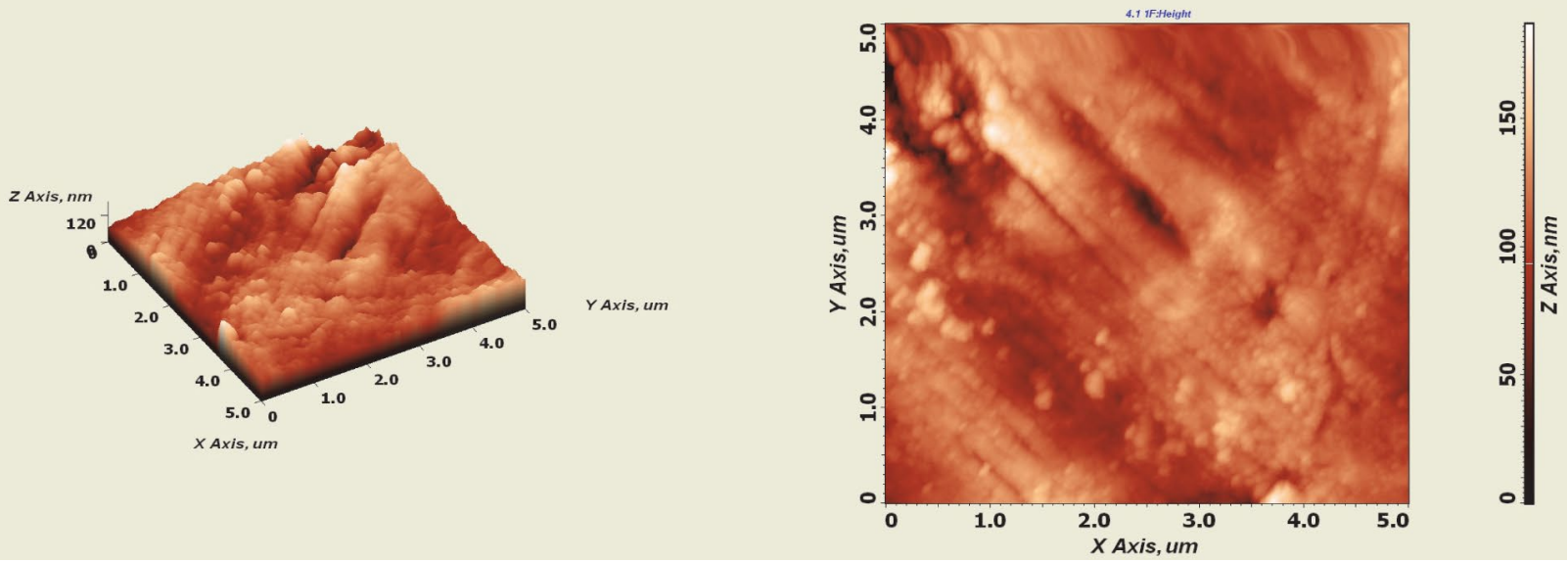

Fig. 7. AFM images of the uncrosslinked and cross linked PVA-PES membranes used in the present study (a: PVA-PES uncrosslinked; b: PVAPES-0.2\% borax; c: PVA-PES-0.5\% borax)

percent elongation of the membrane increased significantly after cross linking with borax. Maximum tensile strength of the uncrosslinked PVA-PES composite membrane was $2.15 \mathrm{~N} / \mathrm{mm}^{2}$ which rose to 2.29 and $2.54 \mathrm{~N} / \mathrm{mm}^{2}$ for PVA-
PES, composite membranes with $0.5 \%$ and $0.2 \%$ Borax respectively. Modulus of elasticity of the borax cross-linked composite membranes was marginally higher than their uncross-linked counterpart. Similar observation for ten- 
sile properties were reported in case of Ethylene 1-Octene Copolymer film on addition of Metallocene in the blend of Metallocene and Ziegler-Natta catalysts. ${ }^{35,36}$ In another study, the elongation at break was found to increase linearly to about $50 \mathrm{wt} \%$ of metallocene polyethylene content in the blend of high-density polyethylene (HDPE)-metallocene polyethylene (MCPE) and polypropylene (PP)metallocene polyethylene (MCPE) ${ }^{37}$ It is noteworthy to mention that there is a small decrease in the tensile strength of $0.5 \%$ borax cross-linked composite membrane as compared to $0.2 \%$ borax cross-linked one. This was plausibly due to sub-microscopic cracks developed from internal stresses as a result of shrinkage or thermal changes after cross-linking. ${ }^{38}$ However, further investigations need to be carried out to ascertain the observation. Cross-linking results in the increase of strength and reduced mobility of the molecular segments. Theoretically it is expected that tensile strength increases with cross-linking density as weak van der Waals' bonds being replaced by strong covalent bonds. It is noteworthy to mention that a little cross-linking may increase the tensile strength, but high degrees of cross-linking could drastically decrease tensile strength and make the polymer very brittle. Therefore, an optimum dose of the cross linker should be care- fully chosen to obtain a suitable composite membrane for pervaporation.

\section{8 Swelling Study}

Swelling of dense polymeric membrane plays a key role in the transport of molecules during pervaporation by increasing the free volume. The greater the affinity between solvent and polymer, the higher is the swelling. As a result, the membrane becomes more open and facilitates more liquid to move through, which in turn influences both permeability and selectivity.

Hence it is worth analyzing the swelling behavior of the composite membranes in feed solutions to study its chemical characteristics. Fig. 8 represents the degree of swelling of both cross linked and uncrosslinked composite membranes used in the present work as a function of feed water concentration (by volume\%) at a fixed temperature of $30^{\circ} \mathrm{C}$. The figure indicates that the degree of swelling increased almost linearly with increasing water content in the feed mixture. Uncross linked PVA-PES membrane exhibited as high as $59.4 \%$ degree of swelling at $80 \%$ feed water concentration. But the water uptake propensity substantially reduced in the borax crosslinked

Table 3. Mechanical Property of PVA-PES composite membranes cross linked with borax. (The figures in the bracket in column 5 indicate standard deviation.)

\begin{tabular}{lcccc}
\hline Membrane Name & $\begin{array}{c}\text { Max Tensile } \\
\text { strength } \\
\left(\mathbf{N} / \mathbf{m m}^{2}\right)\end{array}$ & $\begin{array}{c}\text { Max } \\
\text { Strain } \\
\mathbf{( \% )}\end{array}$ & $\begin{array}{c}\text { \% Elongation } \\
\text { at Max }\end{array}$ & $\begin{array}{c}\text { Modulus } \\
\text { of Elasticity } \\
\left(\mathbf{N} / \mathbf{m m}^{2}\right)\end{array}$ \\
\hline (PVA-PES) & 2.15 & 9.46 & 8.84 & $17.565( \pm 0.54)$ \\
(PVA-PES-Borax 0.5\%) & 2.2916 & 10.678 & 10.678 & $21.4616( \pm 0.37)$ \\
$($ PVA-PES-Borax 0.2\%) & 2.5416 & 12.438 & 12.438 & $20.4347( \pm 0.39)$ \\
\hline
\end{tabular}

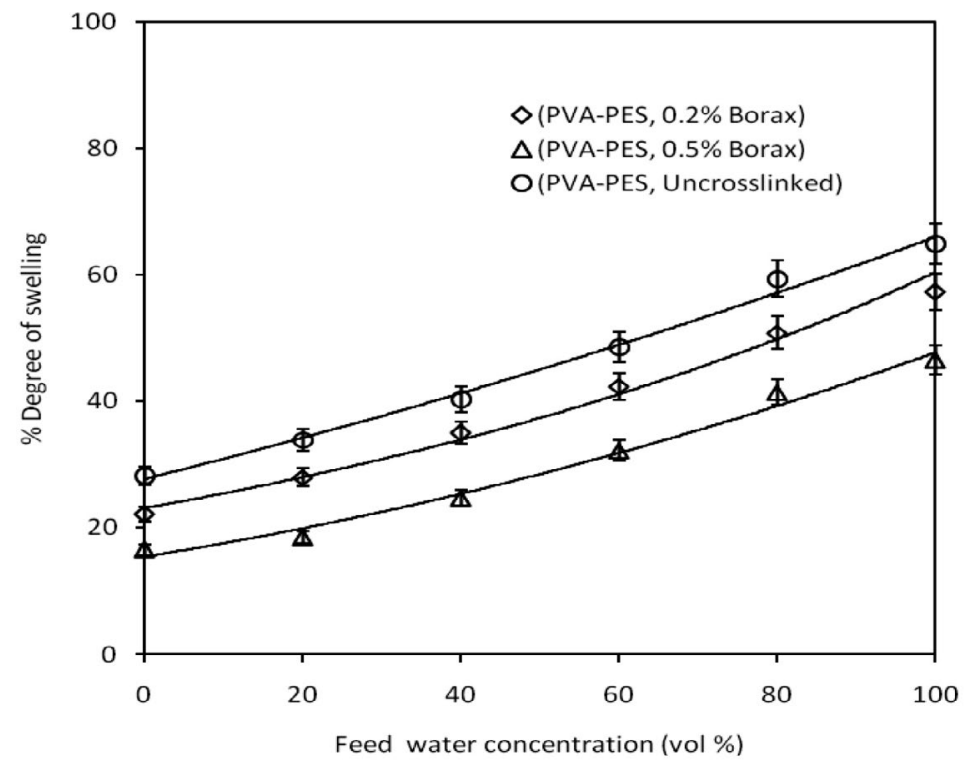

Fig. 8. Percentage degree of swelling as a function of feed water concentration at a constant temperature. 
membranes. At $80 \%$ feed water concentration the degree of swelling was found out to be $58.2 \%$ and $48.7 \%$ for PVAPES $-0.2 \%$ borax and PVA-PES- $0.5 \%$ borax membranes respectively.

During swelling the polymer structure expands as the trapped solution occupies the free volume in the matrix and penetrates into the network of the polymer chains to swell them. The effect of swelling may give rise to two situations. Firstly, expansion of membrane free volume presumably facilitates the larger molecules to pass, thereby increasing permeability and reducing selectivity. Additionally compaction of membrane pores could also occur leading to an increase in selectivity and reduction in permeability. However, our subsequent studies of flux and permeability with the borax cross-linked composite membranes corroborate the former assumption as pervaporation membranes are mostly dense in nature. Degree of swelling of $0.2 \%$ borax cross linked composite was less than that of $0.5 \%$ borax cross linked counterpart. This was probably due to the fact that addition of more cross-linker might have reduced membrane free volume resulting in restricted segmental motion. ${ }^{39}$

\section{9. Flux and Separation Factor}

Flux and separation factors are the two important performance indices of pervaporation membranes. In addition to the membrane structure and morphology, these indices are influenced by the physico-chemical parameters of the process such as temperature, feed concentration and feed flow rate. However, in the following section we report the effect of only feed flow rate on total flux and separation factor at a constant temperature and feed concentration. Fig. 9 represents total pervaporation flux and separation factor as a function of feed flow rate.
For all the membranes, cross linked or otherwise, total pervaporation flux was found to increase with feed flow rate whereas the separation factor decreased. At a flow rate of $0.06 \mathrm{~m}^{3} / \mathrm{h}$ total pervaporation flux was estimated to be $8.81 \mathrm{~m}^{3}(\mathrm{STP}) / \mathrm{m}^{2} \mathrm{~h}$ and $7.21 \mathrm{~m}^{3}(\mathrm{STP}) / \mathrm{m}^{2} \mathrm{~h}$ for $0.2 \%$ and $0.5 \%$ borax cross linked PVA-PES composite membranes respectively, while for the uncrosslinked PVA-PES composite the flux was $7.85 \mathrm{~m}^{3}(\mathrm{STP}) / \mathrm{m}^{2} \mathrm{~h}$. Separation factor was found to be 3.50 at a flow rate of $0.02 \mathrm{~m}^{3} / \mathrm{h}$ for $0.2 \%$ borax crosslinked membrane, which reduced to 2.45 at $0.06 \mathrm{~m}^{3} / \mathrm{h}$ flow rate. For $0.5 \%$ borax cross-linked membrane the highest separation factor was only 1.54 at a flow rate of $0.02 \mathrm{~m}^{3} / \mathrm{h}$ and it dropped to 1.05 when flow rate was increased to $0.06 \mathrm{~m}^{3} / \mathrm{h}$. Both in terms of flux and separation factor PVA-PES- $0.2 \%$ borax composite membrane was found superior to PVA-PES- $0.5 \%$ borax crosslinked and its uncrosslinked counterpart. Doping of excess cross linkers led to the reduction in the membrane free volume as discussed in the earlier section. A drop of the separation factor with increased borax loading could also be reasoned from the poor interfacial adhesion between the borax particles and the polymer matrix. Increase of feed flow rate results in the increase in turbulence at the membrane surface facilitating augmentation of pevaporation flux. As the turbulence increases, the boundary layer thickness decreases and the likelihood of concentration polarization on the upstream side of membrane diminishes as well. This implies that the water concentration near membrane surface approaches to that in the bulk phase ${ }^{9}$ with swellable hydrophilic channels of PVA matrix providing available paths leading to facile permeation flux as feed water content increases. ${ }^{6}$ Moreover, Jafari et al. (2012) demonstrated by a computational fluid dynamics (CFD) study that increasing feed flow rate can enhance feed kinetic energy substantially which in turn increases the extent of turbu-

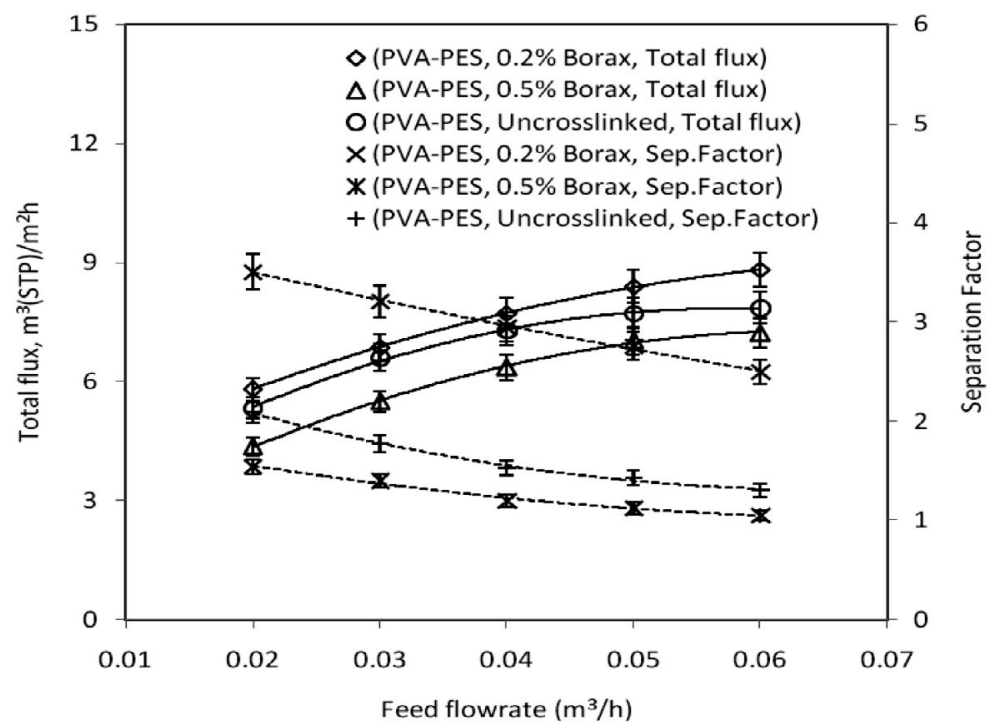

Fig. 9 Total pervaporation flux and separation factor as a function of feed flow rate in the pervaporation of EG-water system (Temperature: $45^{\circ} \mathrm{C}$, Feed concentration: $80 \%$ Ethylene glycol by volume) 
lence. ${ }^{7}$ But at the same time a reverse trend was observed in case of separation factor plausibly due to the less pronounced coupling effect between EG and water molecules at the prevailing feed concentration of the present study. Further this could be due to the weaker EG-water hydrogen bonding interactions leading to low mutual drag between water and EG molecules and decelerating transport of EG molecules. ${ }^{3,11}$ However, literature reports contradictory observations of separation factor behavior with changing feed flow rate in the pervaporation. While a host of studies observed the decreasing trend of separation factor with increasing feed flow rate, ${ }^{6,9}$ a few other reported the reverse trend. ${ }^{7,11}$ Therefore, it is imperative to carry out further rigorous experiment in this direction to ascertain the effect of flow rate on the flux and separation factor using a wide concentration of feed mixture.

\section{10. Permeability, Selectivity and Diffusion Coefficient}

Water permeability and selectivity of the membranes used in the present study as a function of feed flow rate are presented in Table 4. Water permeabilities of all the membranes were found to increase with the increasing feed flow rate while the membrane selectivities decreased. Highest water permeability of 14.56 barrer was exhibited by PVA-PES- $0.2 \%$ borax membrane at a flow rate of 0.6 $\mathrm{m}^{3} / \mathrm{h}$, whereas at the same flow rate the water permeabilities of PVA-PES-0.5\% and PVA-PES uncrosslinked membranes were 10.02 and 11.12 barrer respectively. Selectivity of PVA-PES- $0.2 \%$ borax composite membrane was found out to be 3.65 at $0.02 \mathrm{~m}^{3} / \mathrm{h}$ feed flow rate.

The reason for the increasing water permeability with increasing flow rate can be attributed to the promotion of turbulence at the membrane surface and which was most effective in $0.2 \%$ borax cross linked membrane compared to $0.5 \%$ borax cross-linked and the uncrosslinked ones. The increase in turbulence of feed solution resulted in the decrease of boundary layer thickness. Therefore, mass transfer resistance of boundary layer on the upstream of membrane decreased as well, leading to increased water permeability. Transport of solute during pervaporation is predominantly governed by solution diffusion mechanism and therefore estimation of diffusion coefficients of both

Table 4. Water permeability and selectivity of the membranes used in the present study as a function of feed flow rate. (Each experimental data point is the average of three readings; the figures in the bracket from column 2 to column 7 indicate standard deviation.)

\begin{tabular}{|c|c|c|c|c|c|c|}
\hline \multirow[b]{2}{*}{$\begin{array}{l}\text { Feed flow } \\
\text { rate }\left(\mathrm{m}^{3} / \mathrm{h}\right)\end{array}$} & \multicolumn{2}{|c|}{ (PVA-PES-0.2\% Borax) } & \multicolumn{2}{|c|}{ (PVA-PES-0.5\% Borax) } & \multicolumn{2}{|c|}{ (PVA-PES, Uncrosslinked) } \\
\hline & $\begin{array}{c}\text { Water } \\
\text { Permeability (Barrer) }\end{array}$ & $\begin{array}{l}\text { Membrane } \\
\text { selectivity }\end{array}$ & $\begin{array}{c}\text { Water } \\
\text { Permeability (Barrer) }\end{array}$ & $\begin{array}{l}\text { Membrane } \\
\text { selectivity }\end{array}$ & $\begin{array}{c}\text { Water } \\
\text { Permeability (Barrer) }\end{array}$ & $\begin{array}{l}\text { Membrane } \\
\text { selectivity }\end{array}$ \\
\hline 0.02 & $9.97( \pm 0.35)$ & $3.65( \pm 0.19)$ & $5.36( \pm 0.21)$ & $1.61( \pm 0.32)$ & $8.66( \pm 0.27)$ & $2.15( \pm 0.42)$ \\
\hline 0.03 & $11.73( \pm 0.41)$ & $3.34( \pm 0.24)$ & $7.29( \pm 0.17)$ & $1.42( \pm 0.30)$ & $10.29( \pm 0.22)$ & $1.82( \pm 0.30)$ \\
\hline 0.04 & $13.06( \pm 0.29)$ & $3.06( \pm 0.35)$ & $8.61( \pm 0.0 .40)$ & $1.26( \pm 0.28)$ & $10.91( \pm 0.34)$ & $1.56( \pm 0.28)$ \\
\hline 0.05 & $14.09( \pm 0.32)$ & $2.86( \pm 0.14)$ & $9.32( \pm 0.31)$ & $1.18( \pm 0.13)$ & $11.32( \pm 0.18)$ & $1.45( \pm 0.23)$ \\
\hline 0.06 & $14.56( \pm 0.27)$ & $2.58( \pm 0.22)$ & $10.02( \pm 0.25)$ & $1.10( \pm 0.26)$ & $11.12( \pm 0.15)$ & $1.32( \pm 0.14)$ \\
\hline
\end{tabular}

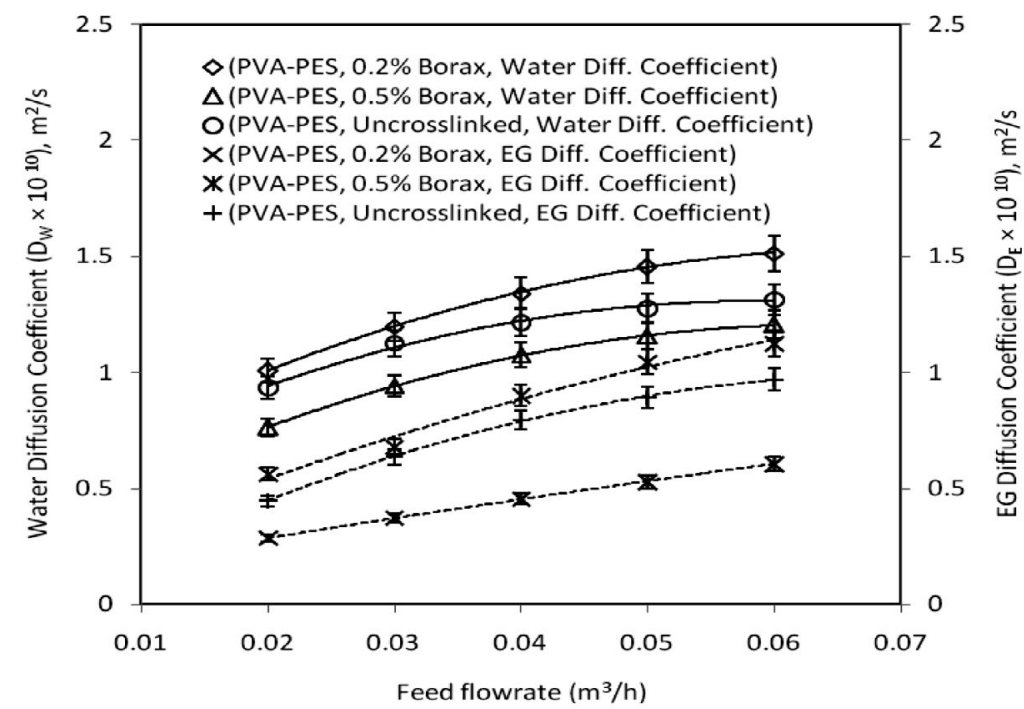

Fig. 10. Water and ethylene glycol diffusion coefficient as a function of feed flow rate in the pervaporation of EG-water mixture (Temperature: $45^{\circ} \mathrm{C}$, Feed concentration: $80 \%$ Ethylene glycol by volume) 
EG and water assumes importance. Water and EG diffusion coefficients as a function of feed flow rate are presented in Fig. 10. As shown in the figure both the EG and water diffusion coefficients increased with increasing feed flow rate. However the magnitude of water diffusion coefficients was higher than EG diffusion coefficients under all experimental conditions. At a feed flow rate of $0.06 \mathrm{~m}^{3} / \mathrm{h}$ diffusion coefficients of water were estimated to be $1.51 \times$ $10^{-10} \mathrm{~m}^{2} / \mathrm{s}$ and $1.19 \times 10^{-10} \mathrm{~m}^{2} / \mathrm{s}$ in the PVA-PES- $0.2 \%$ and PVA-PES- $0.5 \%$ composite membranes respectively. But diffusion coefficients of EG at the same flow rate were 0.61 $\times 10^{-10} \mathrm{~m}^{2} / \mathrm{s}$ and $1.12 \times 10^{-10} \mathrm{~m}^{2} / \mathrm{s}$ for PVA-PES- $0.2 \%$ and PVA-PES-0.5\% membranes respectively. The higher diffusion coefficient of water compared to EG may be ascribed to the smaller size (kinetic diameter) of water molecules than EG. ${ }^{27}$ It was also observed that the diffusion coefficients of water decreased as borax content in the PVA-PES composite increased from 0.2 to $0.5 \%$. This was probably due to the reduction of membrane free volume resulting in restricted segmental motion of the diffusing water molecules through the composite membrane network. ${ }^{39}$ In addition the mutual interaction between EG-water molecules presumably reduced plasticization effect, which in turn suppressed the sorption as well as diffusion.

\section{11. Effect of Feed Temperature}

Intrinsic membrane permeability of ethylene glycol and water as a function of feed temperature and with a fixed feed concentration of $80 \%$ (vol) ethylene glycol for all three prepared membrane is presented in Fig. 11.

A perusal of Fig. 11 indicates that permeability of both water and ethylene glycol increase with increase in temperature, although the magnitude of permeability of water was higher than that of ethylene glycol. It was also observed (data not shown) that the membrane selectivity decreased with increase in temperature. The PVAPES- $0.2 \%$ borax cross linked membrane shows highest water permeability and lowest ethylene glycol permeability than other two membranes at any feed temperature. The processes involved in permeation, sorption and diffusion are activated processes and the temperature effect can be described by Arrhenius type relationship. ${ }^{12}$ The relationship of flux or permeance of a penetrant across a membrane with operating temperature can be described by the Arrhenius equations as follows:

$$
X=X_{o} \exp \left(\frac{-E_{X}}{R T}\right)
$$

where $X$ is the pervaporation flux $(J), X_{0}$ is the pre-exponential factor (permeation rate constant) $\mathrm{R}$ is the universal gas constant $(\mathrm{J} / \mathrm{mol} \mathrm{K}), \mathrm{T}$ is the operation temperature $(\mathrm{K})$, and $E_{\mathrm{X}}$ is the apparent activation energies of permeance $(\mathrm{kJ} / \mathrm{mol})$. The apparent activation energy of water permeation $\left(E_{\mathrm{PW}}\right)$ and ethylene glycol permeation $\left(E_{\mathrm{EG}}\right)$ for all three membranes are presented in Table 5. The results indicate that the activation energy of water permeation through PVA-PES- $0.2 \%$ borax cross linked membrane was significantly lower than those of ethylene glycol permeation, suggesting a higher separation efficiency of the membranes. If the activation energy is positive, the permeation flux increases with an increase in temperature, which has also been reported in most pervaporation experiments in the literature. ${ }^{40,41}$ The present study also corroborates the same observation. Due to its molecular size and shape, the activation energy of diffusion for ethylene glycol will be greater than that for water. As the water content in the feed decreases the polymeric membrane become less swollen and the mobility of chain segments decreases, thus increasing

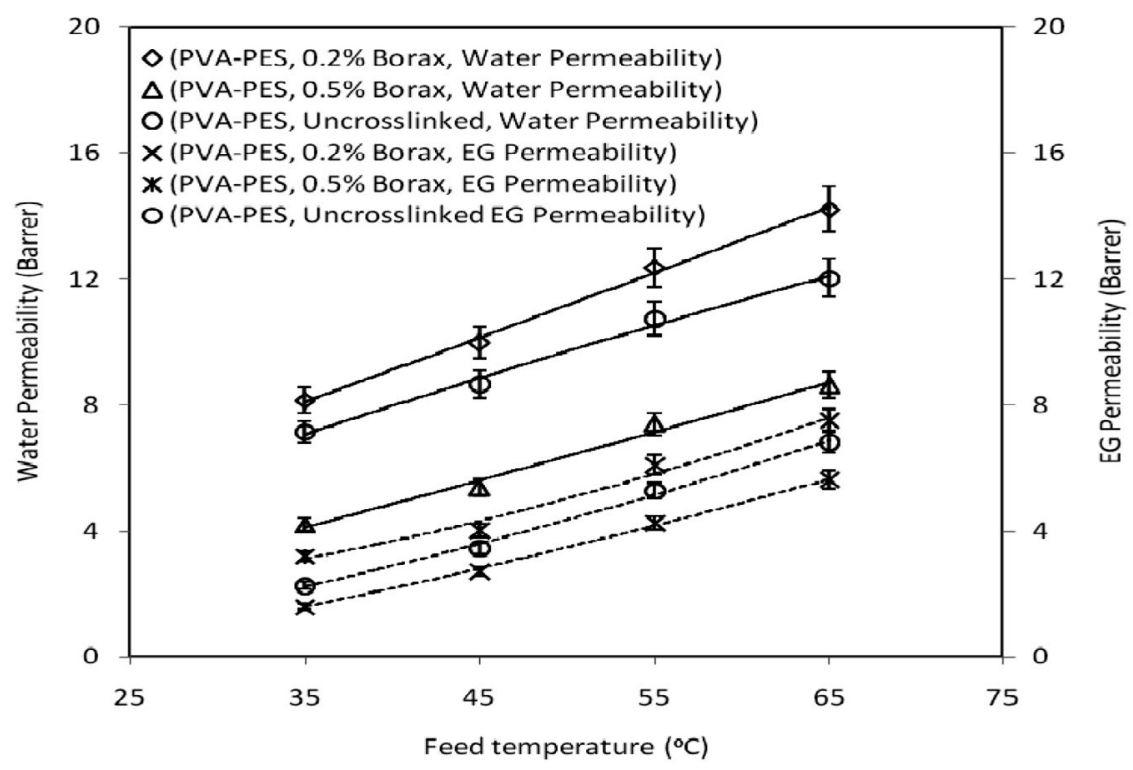

Fig.11. Water and ethylene glycol permeability as a function of feed temperature 
the energy required for the diffusive jump of ethylene glycol molecules. The interaction between permeants is thought to have an enhancing effect on the permeation activation energy because associated molecules require more energy for permeation than isolated molecules. In contrast, the plasticization action diminishes the activation energy by making the polymeric chain segments more flexible.

Table 5. Apparent activation energy of water and ethylene glycol permeation through PVA-PES composite membranes cross linked with borax.

\begin{tabular}{ccc}
\hline $\begin{array}{c}\text { Membrane } \\
\text { Name }\end{array}$ & $\begin{array}{c}\text { Water activation } \\
\text { energy (kJ/mol) }\end{array}$ & $\begin{array}{c}\text { Ethylene glycol } \\
\text { activation energy } \\
(\mathbf{k J} / \mathbf{m o l})\end{array}$ \\
\hline (PVA-PES) & 15.40 & 32.38 \\
(PVA-PES-Borax 0.5\%) & 21.57 & 25.80 \\
(PVA-PES-Borax 0.2\%) & 16.32 & 36.69 \\
\hline
\end{tabular}

\section{Conclusions}

Borax cross linked PVA-PES composite membranes were prepared for the pervaporation dehydration of EG-water mixtures. The PVA layers were successfully cross linked with two different concentrations e.g. $0.2 \%$ and $0.5 \%$ (by weight) borax as cross linking agents although $0.2 \%$ borax crosslinked PVA-PES composite was found better in terms of flux, permeability and separation factor. The as-prepared composite membranes were characterized by FTIR, XRD, TGA, DSC, FESEM, AFM, swelling degree and mechanical property analyses. The salient findings from the above tests indicate that borax could be effectively cross linked in the PVA network imparting adequate thermal and mechanical stability, over a wide temperature range. Crosslinking could reduce crystallinity and hydrophilicity of membrane thereby affecting swelling and permeation behavior. The resulting $0.2 \%$ borax cross linked PVA-PES composite membrane exhibited a separation factor of 3.50 with a pervaporation flux of $8.81 \mathrm{~m}^{3}(\mathrm{STP}) / \mathrm{m}^{2} \mathrm{~h}$ for $80 \%$ EG in the feed at $70{ }^{\circ} \mathrm{C}$. Although pervaporation flux and diffusion coefficients of both EG and water increased with increasing feed flow rate, separation factor and selectivity decreased. The diffusion coefficient of water was higher than that of EG at a fixed temperature and feed concentration. The long-term investigation of process conditions showed that the composite membranes displayed the desirable operating and structural stability. In essence the findings of the present study indicate that the borax crosslinked PVA-PES composite membrane proves suitable for the dehydration of EG-water mixture in a wide range of concentrations.

\section{Acknowledgements}

The authors are grateful to the Sophisticated Instrumentation Centre for Advanced Research and Testing (SI-
CART) for their valuable help to carry out certain analyses. Suggestions by the anonymous reviewers to improve the manuscript are also gratefully acknowledged.

\section{1. Nomenclature}

EG ethylene glycol

TG thermogravimetry

FTIR Fourier transformed infrared

AFM Atomic force microscopy

FE-SEM Field Emission Scanning electron microscopy

PVA Polyvinyl alcohol

PES Polyether sulfone

$W_{\text {wet }} \quad$ weight of swallow membrane (g)

$W_{d r y} \quad$ weight of dry membrane (g)

$P_{m, i} \quad$ membrane permeability $\left(\mathrm{cm}^{3}(\mathrm{STP}) \mathrm{cm} / \mathrm{cm}^{2}\right.$ $\mathrm{s} \mathrm{cm} \mathrm{Hg}$ )

$J_{i} \quad$ mass flux $\left(\mathrm{kg} / \mathrm{m}^{2} \mathrm{~h}\right)$

$x \quad$ mole fraction of feed

y mole fraction of permeate

$P_{\mathrm{p}} \quad$ permeate pressure

$P_{s} \quad$ saturated vapor pressure

$j_{\mathrm{i}} \quad$ molar flux $\left(\mathrm{cm}^{3}(\mathrm{STP}) / \mathrm{cm}^{2} \mathrm{~s}\right)$ of component ' $\mathrm{i}$ '

$v_{i}^{G} \quad$ molar volume of gas i (22.4 l(STP)/mol)

$D_{i} \quad$ diffusion coefficient $\left(\mathrm{m}^{2} / \mathrm{s}\right)$

Greek letters

$\beta \quad$ Ideal separation factor

$\alpha \quad$ Membrane selectivity

$\gamma \quad$ Activity coefficient

$\delta \quad$ membrane thickness $(\mathrm{mm})$

\section{References}

1. J. Xi, D. Ding, Y. Shao, X. Liu, G. Lu, Y. Wang, ACS sustainable Chem Eng. 2014, 10, 2355. DOI:10.1021/sc500380c

2. D. Sun, P. Yang, Sun, H-L., Li, B-B. Euro. Polymer J. 2015, 62,155. DOI:10.1016/j.eurpolymj.2014.11.027

3. M. Shahverdi, T. Mohammadi, A. Pak, J. Appl. Polym. Sci. 2011, 119, 1704. DOI:10.1002/app.32862

4. D. Wu, J. Martin, J. Du, Y. Zhang, D. Lawless, X. Feng, J Membr. Sci. 2015, 493, 622. DOI:10.1016/j.memsci.2015.07.016

5. Y. Wang, T. S. Chung, B.W. Neo, M. Gruender J Membr. Sci. 2011, 378, 339. DOI:10.1016/j.memsci.2011.05.020

6. B. Baheri, M. Shahverdi, M. Rezakazemi, E. Motaee, T. Mohammadi Chem. Eng. Commu. 2015, 202, 316.

DOI:10.1080/00986445.2013.841149

7. M. Jafari, A. Bayat, T. Mohammadi, M. Kazemimoghadam, Chem Engg Res Design, 2012, 91, 2412.

DOI:10.1016/j.cherd.2013.04.016

8. C. Yu, C.Zhong, Y.Liu, X. Gu, G. Yang, W.Xing, N.Xu, Chem Engg Res Design. 2012, 90, 1372. DOI:10.1016/j.cherd.2011.12.003

9. S. Y. Hu, Y. Zhang, D. Lawless, X. Feng, J Membr. Sci. 2012, 418, 34. DOI:10.1016/j.memsci.2012.06.010 
10. P. S. Rao, S. Sridhar, M. Y. Wey, A. Krishnaiah, Ind. Eng. Chem. Res. 2007, 46, 2155. DOI:10.1021/ie061268n

11. R. Guo, X. Fang, H. Wu, Z. Jiang, J Membr. Sci. 2008, 322, 32. DOI:10.1016/j.memsci.2008.05.015

12. D. Rana, T. Matsuura, Chem. Rev. 2010, 110, 2448. DOI:10.1021/cr800208y

13. R. Y. M. Huang, R. Pal, F. G. Y. Moon, J. Membr. Sci. 2000, 167, 275. DOI:10.1016/S0376-7388(99)00293-8

14. A. Jonsson, B. Jonsson, J. Membr. Sci. 1991, 56, 49. DOI:10.1016/0376-7388(91)85015-W

15. W. U. Hong, L. I. Xianshi, N. I. E. Mingchen, L. I. Ben, J. Zhongyi, Chinese J. Chem. Eng. 2011, 19, 855.

DOI:10.1016/S1004-9541(11)60088-8

16. H. K. Dave, K. Nath, J Water Proc. Eng. 2016, 14, 124.

17. R. W. Baker, J. G. Wijmans, Y. Huang, J. Membr. Sci. 2010, 348, 346. DOI:10.1016/j.memsci.2009.11.022

18. O. Koysuren, M. Karaman, M. Dinc, J Appl. Polym. Sci. 2012, 124, 2736. DOI:10.1002/app.35035

19. M. Kobayashi, Y. Kitaoka, Macromol Symp. 1997, 114, 303. DOI:10.1002/masy.19971140141

20. G. Ramadevudu, L., S.Rao, S., M. Shareeffuddin, C. Narasimha, M., Lakshmipathi, Rao M. Global J Sci Frontier Res Phys Space Sci. 2012, 12, 41.

21. P. Das, S. K. Ray, S. B. Kuila, H.S. Samanta, N.R. Singha, Sep. Purif. Technol. 2011, 81, 159.

DOI:10.1016/j.seppur.2011.07.020

22. P. S. Rachipudi, M. Y. Kariduraganavar, A. A. Kittur, A. M. Sajjan, J membr. Sci. 2011, 383, 224.

23. D. Rana, B. M. Mandal, S. N. Bhattacharyya, Macromolecules. 1996, 29, 1579.

24. D. Rana, K. Bag, S. N. Bhattacharyya, B. M. Mandal, J. Polym. Sci: Part B: Polym. Phys. 2000, 38, 369.

DOI: 10.1002/(SICI) 1099-0488(20000201)38:3<369: :AID-POLB3>3.0.CO;2-W

25. D. Rana, B. M. Mandal, S. N. Bhattacharyya, Polymer. 1996, 37, 2439. DOI:10.1016/0032-3861(96)85356-0
26. D. Rana, B. M. Mandal, S. N. Bhattacharyya, Polymer. 1993, 34, 1454. DOI:10.1016/0032-3861(93)90861-4

27. S. B. Kuila, S. K. Ray, P. Das, N. R. Singha, Chem. Eng Processing. 2011, 30, 391. DOI:10.1016/j.cep.2011.02.011

28. Y. Nishino, John, Manley R. S. Macromolecules. 1988, 21, 1270.

29. S. S. Kulkarni, A. A. Kittur, M.I. Aralaguppi, M.Y. Kariduraganavar, J Appl. Polymer Sci. 2004, 94, 1304. DOI:10.1002/app.21088

30. Z. Chen, D. Rana, T. Matsuura, Y. Yang, C. Q. Lan, Sep. Purif. Technol. 2014, 133, 303. DOI:10.1016/j.seppur.2014.07.015

31. D. Rana, T. Matsuura, R. M. Narbaitz, K. C. Khulbe, J Appl. Polymer Sci. 2006, 101, 2292. DOI:10.1002/app.23723

32. Y. Yang, D. Rana, T. Matsuura, C. Q. Lan, Sep. Purif. Technol. 2016, 164, 56. DOI:10.1016/j.seppur.2016.03.023

33. Z. Chen, D. Rana, T. Matsuura, D. Meng, C. Q. Lan, Chem. Engg. J. 2015, 276, 174. DOI:10.1016/j.cej.2015.04.030

34. D. Rana, B. Scheier, R. M. Narbaitz, T. Matsuura, S. Tabe, S. Y. Jasim, K. C. Khulbe, J Membr. Sci. 2012, 409, 346.

DOI:10.1016/j.memsci.2012.04.005

35. D. Rana, K. Cho, T. Woo, B. H. Lee, S. Choe, J Appl. Polymer Sci. 1999, 74, 1169.

DOI:10.1002/(SICI)1097-4628(19991031)74:5<1169::AIDAPP13>3.0.CO;2-W

36. D. Rana, H. L. Kim, H. Kwang, J. Rhee, K. Cho, T. Woo, B. H. Lee, S. Choe, J Appl. Polymer Sci. 2000, 76, 1950.

37. D. Rana, C. H. Lee, K. Cho, B. H. Lee, S. Choe, J Appl. Polymer Sci. 1998, 69, 2441.

DOI:10.1002/(SICI)1097-4628(19980919)69:12 $<2441:$ :AID-APP15>3.0.CO;2-\#

38. K. S. Anseth, C. N. Bowman, L. Brannon-Peppas, Biomaterials, 1996, 17, 1647. DOI:10.1016/0142-9612(96)87644-7

39. H. Qu, Y. Kong, H. Lv, Y. Zhang, J. Yang, D. Shi, Chem. Eng. J. 2010, 157, 60. DOI:10.1016/j.cej.2009.09.044

40. Guo, R., Changlai, H., Ben, L., Zhongyi, J. J. Membr. Sci. 2007, 289, 191. DOI:10.1016/j.memsci.2006.11.055

41. Hu C, Ben L, Guo R, Hong W, Zhongyi, J. Sep. Purif. Techol. 2007, 55, 327. DOI:10.1016/j.seppur.2007.01.005

\section{Povzetek}

Preučevano je bilo odstranjevanje vode iz etilen glikol (EG) - vodne mešanice na laboratorijskem preduparjalniku z uporabo različnih ravnih membran. Polivinil alkohol-polieter sulfonska (PVA-PES) kompozitna membrana je bila sintetizirana in premerežena $\mathrm{z}$ uporabo dveh različnih koncentracij dinatrijevega tetraborata $(0.2$ in $0.5 \%)$. Pripravljenim membranam so okarakterizirali morfologijo, medmolekularne interakcije, termo-mehansko stabilnost ter fizikalno kemijske lastnosti z uporabo vrstične elektronske mikroskopije (FESEM), mikroskopije na atomsko silo (AFM), fourierjeve transformacijske infrardeče spektroskopije (FT-IR), rentgenske difrakcije (XRD), termogravimetrične analize (TGA), diferenčne dinamične kalorimetrije (DSC) in sposobnosti adsorpcije vode. Poleg tega so bile lastnosti membran ovrednotene s faktorjem ločbe, selektivnostjo, propustnostjo in difuzijskim koeficientom topljenca v EG-vodni mešanici pri različnih pretokih napajanja. Tako glede fluksa kot selektivnosti se je PVA-PES membrana zamrežena z $0.2 \%$ borata izkazala boljša od membrane zamrežene z 0.5 \% borata oziroma nezamrežene membrane. Zamreženje kompozitne membrane $\mathrm{z}$ boratom se je odrazilo $\mathrm{v}$ nižji kristaliničnosti in manjšem nabrekanju, a $\mathrm{z}$ izboljšano termično stabilnostjo in mehanskimi lastnostmi. 